\title{
RATAS, CENIZAS Y PERLAS. EL VOCABULARIO DEL COLOR EN LOS INTERIORES DEL SIGLO XVIII \\ RATS, ASH AND PEARLS. COLOR VOCABULARY IN THE INTERIOR OF THE XVIII CENTURY
}

\author{
Carmen Abad Zardoya* \\ Universidad de Zaragoza
}

\section{Resumen}

La Ilustración española se interesó por el color como factor esencial de su proyecto de reforma de las artes secundarias como atestiguan los numerosos manuales que se afanaron en hacer avanzar en el Setecientos las industrias del tinte. Hasta ahora, el gusto por nuevas combinaciones de colores en el siglo XVIII ha sido tratado preferentemente en los estudios dedicados a la indumentaria, asumiendo la historiografía del espacio doméstico las habituales vinculaciones entre colores y estilos a la moda. Sin embargo, otras fuentes hasta ahora poco analizadas desde este punto de vista, como la documentación notarial, pueden matizar de manera sustancial esta imagen. Este artículo recupera, a partir de un corpus de más de doscientos inventarios zaragozanos fechados entre 1700 y 1804, todas las denominaciones de colores utilizadas por los escribanos en su descripción del ajuar doméstico, con el fin de iniciar un estudio de los distintos significados culturales del color a partir de la decoración de la vivienda y de los objetos contenidos en aquella.

Palabras clave: Siglo XVIII, Lexicografía del color, Historia cultural del color, Interiores, Cultura material, Inventarios.

\section{Abstract}

The Spanish Enlightenment saw colour as an essential factor in its reform of the so-called secondary arts or crafts as shown by the numerous recipe-books and handbooks dedicated during the 18th century to the improvement of the art of dyeing. Until the present, the taste for new 18th-century colour combinations has been studied mainly by researchers dedicated to fashion and costume. Their assumptions have been used in the historiography of domestic interiors without further critical discussion. But other sources not so far examined from this point of view, such as notarial inventories of domestic objects, challenges this received image. The present article, based on the study of over two hundred inventories

"E-mail: carabad@unizar.es 
from the city of Zaragoza between 1700 and 1804, examines systematically the colour denominations used by notary clerks in their descrptions of domestic objects with the aim of initiating a study of the different cultural meanings of colour.

Keywords: 18th Century, Colour lexicography, Cultural history of color, Interiors, Material culture, Inventories.

\section{Introducción}

El siglo XVIII, en opinión de muchos, trajo a Europa una renovada cultura del color. Descubrimientos de fórmulas como el revolucionario azul de Prusia, y el interés que nacientes disciplinas científicas mostraron por el color-luz y el colorpigmento son solo algunos de sus síntomas. Eruditos de la época, como el abate Pluche en Francia y el benedictino Martín Sarmiento en España, cultivadores ambos del veterano género de la Historia Natural, escribieron sobre el color en relación a los objetos que arropaban la existencia humana. Mientras el primero glosaba los múltiples beneficios que el color había traído a la vida en $\operatorname{sociedad}^{1}$, el segundo intentaba armonizar ciencia y arte en una peculiar interpretación de la escala cromática newtoniana, para la que proponía una combinatoria análoga a las proporciones musicales ${ }^{2}$. Al margen de estas especulaciones teóricas, la Ilustración española se interesó por el color abrazando el utilitarismo que regía la mayor parte de sus iniciativas. Se apostó por una ciencia práctica del color llamada a jugar un papel destacado en el gran proyecto del Despotismo Ilustrado, la consecución del progreso nacional a través de la reforma de las artes secundarias. De ahí que el arte de la tintura despertase en el siglo XVIII un interés del que participaron, como resaltó Nieto Galán, "comerciantes, fabricantes, artesanos, químicos, tintoreros, boticarios, dibujantes y grabadores"3. En línea con sus apreciaciones, Jesusa Vega analizó en profundidad lo que considera fue una revaloración de las artes del tinte sin precedentes en nuestro país, que se manifestó no solo en el establecimiento de la Oficina del Tinte y en las numerosas disertaciones académicas dedicadas a la materia, sino también en una auténtica explosión bibliográfica de recetarios y manuales que, si bien no obtuvieron el éxito esperado en los talleres profesionales, contaron en compensación con la entusiasta acogida de los aficionados y de los promotores de nuevas industrias locales ${ }^{4}$.

El léxico del color era por entonces sorprendentemente variado y rico en connotaciones, tanto es así que, dentro del marco de los planes de modernización del tinte y las artes textiles, hubo quienes defendieron la necesidad de sujetarlo a una cierta normalización instrumental ${ }^{5}$. Junto a una nomenclatura de carácter técnico que establecía los nombres de los colores a partir de las materias primas que intervenían en su fabricación -un recurso característico del léxico profesional de pintores y tintoreros- se extendía en el habla común, y de paso en la documentación notarial, un vocabulario construido a partir de la evocación de los tonos hallados en la naturaleza. Así, para nombrar un color se escogía como referente la peculiar tonalidad de una flor, de una especia, de una bebida, de un 
tipo de piel o, incluso, el de la misma sangre. A menudo, la acuñación y uso de cierta denominación suponían el reflejo o el nacimiento, según los casos, de una moda, el otro gran fenómeno del siglo, agitado de principio a fin por las controversias entre sus dictados y el discurso moral sobre el lujo. A día de hoy, utilizamos todavía algunas de aquellas denominaciones, pero una parte de ese vocabulario antaño común ha recalado, por ejemplo, en la especializada jerga de los profesionales del mundo del caballo, codificada hacia mediados del siglo XIX. No resulta descabellado suponer que la industrialización y la invención de los colores sintéticos hayan tenido algo que ver en este proceso de fosilización parcial del antiguo lenguaje del color, que ha terminado por refugiarse en el circuito de los saberes y oficios tradicionales.

\section{El color en la apreciación del espacio.}

Como afirmara Jean Baudrillard en relación a los interiores contemporáneos, el color, con su carga de connotaciones culturales, morales y psicológicas, se revela como uno de los principales "valores de ambiente"6. Dicho de otro modo, los colores condicionan de forma decisiva la percepción del espacio, de manera que cualquier tentativa de reconstruir los interiores domésticos del pasado debiera prestar la misma atención que se concede hoy a su uso en objetos y superficies. En los siglos del Antiguo Régimen, la decoración se entendía en buena medida como revestimiento, de manera que el color se apropió de los ambientes preferentemente de la mano de los tejidos, vistiendo paredes, suelos y muebles de un modo similar a como se vestían los cuerpos. La fortuna del mobiliario pintado o lacado, así como la eclosión de la nueva cultura del color que tuvo lugar en el XVIII hacen que, en lo que respecta a los interiores del setecientos, esta propuesta metodológica sea casi un imperativo. A pesar de ello, son pocos los estudios que en España se han ocupado del uso del color en el espacio arquitectónico desde una perspectiva histórica no forzosamente centrada en sus dimensiones simbólicas, motivo de más para resaltar aportaciones como el volumen coordinado por Carmen Gómez Urdáñez ${ }^{7}$ en el que se aborda su empleo no solo en la pintura (Miguel Hermoso) sino también en los revestimientos textiles (Ana Ágreda), por definición reversibles. El gusto por nuevas gamas y combinaciones de colores en el setecientos se ha tratado en los estudios sobre la moda en la indumentaria pero la historiografía del espacio doméstico nos ha acostumbrado a asumir determinadas vinculaciones entre colores y estilos, como el idilio de los pasteles con el rococó o la vocación de mesura de un neoclásico en grises y medios tonos. A grandes rasgos podría parecer suficiente pero un examen de la documentación notarial nos envía señales dignas de ser consideradas con mayor atención. La persistencia de un arraigado gusto por combinaciones de colores intensos que hoy nos resultan inarmónicas, su encaje en una nueva paleta dominada por fríos, claros y pasteles así como el deliberado uso del color para uniformizar los ambientes son algunos fenómenos en los que conviene profundizar. Para ello es necesario comenzar recopilando y descifrando el vocabulario del color en las fuentes notariales. En los apartados que siguen se 
clasifican y analizan todas las denominaciones de colores registradas en dos centenares de inventarios post mortem realizados en Zaragoza entre 1700 y 1804, señalando las equivalencias en catalán extraídas del archivo de protocolos notariales de Barcelona por Rosa Creixell, quien elaboró un listado de los colores de mayor presencia en los inventarios fechados en la Ciudad Condal entre 1739 y 17618. Salvo en una ocasión, los escribanos llevaron a cabo el registro de los bienes sin auxilio de profesionales que ayudasen a la tasación de una determinada partida de bienes, lo que hubiera supuesto la utilización de un léxico técnico diferente al que se pretende reflejar aquí. No se trata de formular un glosario del color con vías a identificar cada tono -para ello ya existen completísimos diccionarios especializados ${ }^{9}$ - sino de dar el primer paso en un estudio cultural del color vinculado a la decoración y al ajuar domésticos, lo que incluye la indumentaria personal, los revestimientos, el mobiliario y la lencería de casa.

\section{Jalea de tierras}

A juzgar por las recreaciones históricas de viviendas que, una y otra vez, nos brindan el cine o la televisión, la mayoría de los directores artísticos parecen empeñados en convencernos de que cualquier tiempo pasado fue marrón. Sin embargo, quien haya entrado en contacto con los inventarios medievales y modernos no tarda en descubrir un panorama bien distinto a esa jalea de tierras y ocres, abriéndose paso en un mundo repleto de suntuosos tejidos en colores variados intensos que, a menudo, se valoran de forma extraordinaria en las tasaciones ${ }^{10}$. Esto no ha impedido, sin embargo, que los pardos llegaran a formar una extensa familia en la que muchos de los nombres se construyeron por alusión a sustancias valiosas -especias y estimulantes de moda fundamentalmente-, tal vez con la intención de dotar de encanto a una gama cromática vinculada secularmente al campesinado y al clero regular. En la documentación consultada, el castaño o "color de castaña" sólo se usó en referencia al pelaje de los semovientes, si bien en el cambio de siglo podemos verlo utilizado, de forma excepcional, en relación a prendas de vestir confeccionadas con pieles ${ }^{11}$. Entre los tejidos empleados en decoración e indumentaria, el tono más claro es el "color de canela", que remite a la especia homónima, de la misma manera que el "color clabillo" responde al marrón profundo del clavo de olor. El segundo, tanto en damascos como en paños de lana y estameña, es el más utilizado. Los tres estimulantes de moda integrados en la nueva sociabilidad, -café, chocolate y tabaco- dan nombre a otras tantas tonalidades oscuras de marrón. El "color chocolate" sería el más cálido de los tres ya que, desde su introducción en la dieta de los españoles, al chocolate se le añadía un toque rojizo de nuez de bija -el achiote de los brebajes precolombinos- que enmascaraba el aspecto terroso del cacao desleído12. El "amusco" o "amuscado" se conocía también como "musco" o almizcle, perfume de origen animal de apariencia untuosa y oscura que tuvo múltiples usos en la cosmética y la confitería modernas. En el arte de la tapicería al amusco se le llamó también "color de raíz", y se consideraba uno de los colores 
maestros a partir de cuya mezcla se obtenían los distintos "matices" o mezclas 13 . El amusco se empleó preferentemente en géneros textiles pero también encontramos noticias de carpinterías -coches sobre todo- pintados en este color ${ }^{14}$. La expresión "color de hábito", aplicada exclusivamente a prendas de vestir confeccionadas en géneros de lana, remite a la indumentaria de ciertas órdenes religiosas. Las fuentes zaragozanas llegan a distinguir entre el "color del hábito de San Francisco" y el "color de hábito de Nuestra Señora del Carmen" que suponemos de tonalidad bermejiza, como nuestro marrón carmelita.

En lo que toca al mobiliario, los pardos y sus matices están representados en las técnicas de pintura imitativa de maderas nobles o exóticas, de manera que, más que colores, las expresiones denotan la presencia de veteados realizados con sombra sobre un fondo teñido en una determinada tonalidad de marrón ${ }^{15}$. En la primera mitad de siglo -y en relación a una marcada pervivencia del gusto por las camas de granadillo con apliques broncíneos- abundan las noticias de muebles "color de granadillo"16. En la segunda mitad domina el color de nogal, con alguna que otra referencia al "color de raíz de oliva". En la última década y en los primeros años del XIX triunfará el color de caoba en un amplio espectro de hogares ${ }^{17}$.

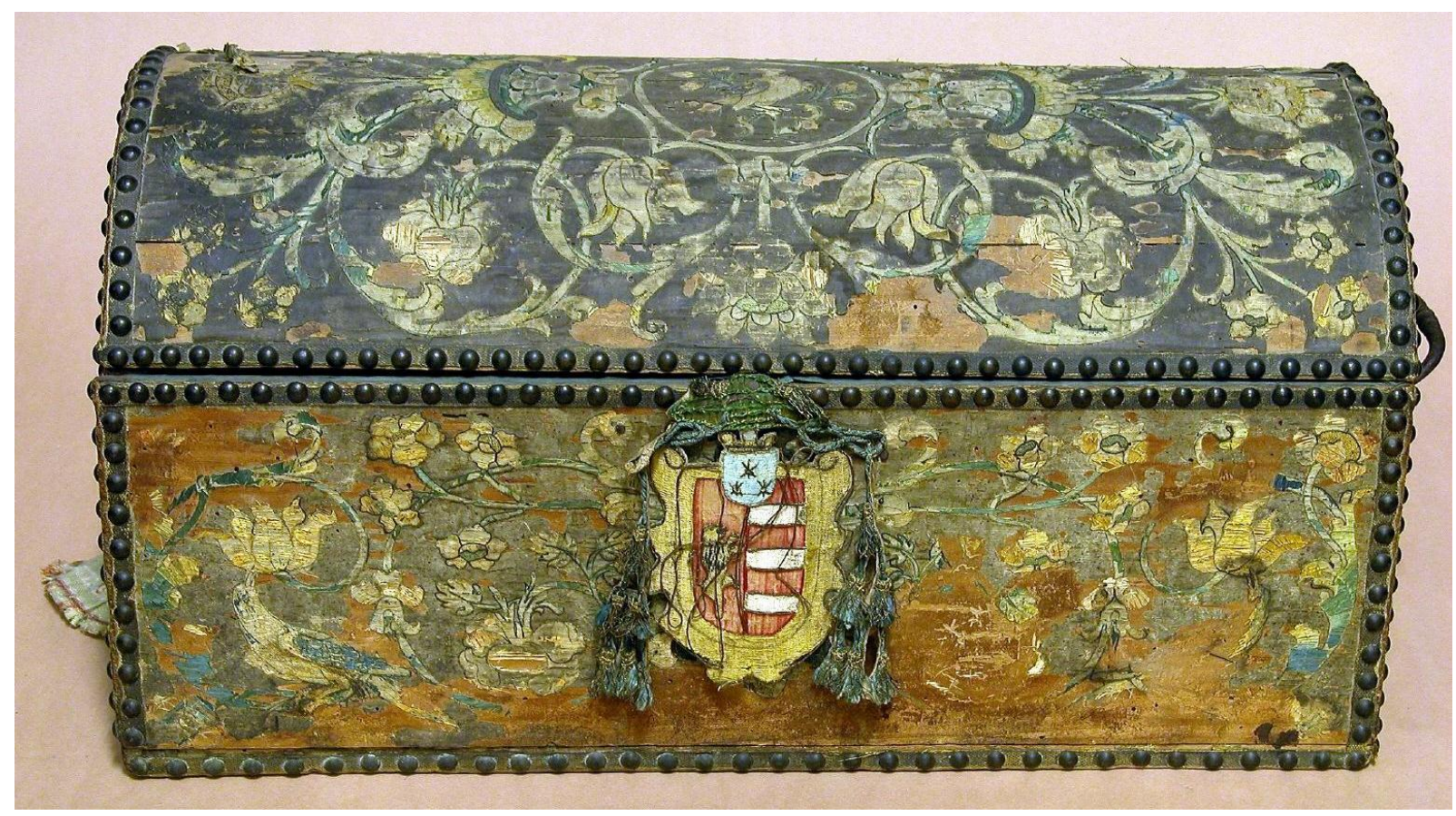

Fig 1. Baúl ensayalado con decoración bordada en una amplia gama de colores. Datación imprecisa, entre 1600 y 1800. MNAD, inv. CE19258. 
Por los mismos años aparecen en los inventarios prendas de vestir y tejidos de "color de pulga", ejemplo representativo del papel de la moda en la configuración de este vocabulario, una tendencia que, en esta ocasión, se dicta con acento francés. Es probable que su éxito descansara en la dudosa pero sugestiva anécdota que explica su origen. Al parecer, el marrón había causado furor en Versalles durante el verano de 1775, y tan presente estuvo en la vida cortesana que se atribuyó al propio rey un comentario jocoso sobre el tono de moda, al que se refirió como "color de pulga". A partir de ahí, las nuevas variantes de pardos se rebautizaron tomando partes de la anatomía del parásito, que suponemos tan impertinente y numeroso como la versallesca tribu ${ }^{18}$. En la documentación zaragozana, el color de pulga se empleó sobre todo en indumentaria masculina confeccionada exclusivamente con géneros de seda ${ }^{19}$.

\section{Y se hizo la luz: perla, nácar, porcelana y leche}

Una de las novedades del siglo en cuanto a la decoración, es una progresiva preferencia por los tonos pasteles y los colores claros o de saturación débil, tendencia que, unida a una nueva concepción de la iluminación -cenital y de reverbero- articulada a base de cornucopias, arañas y espejos de entrepaño, acabaría por reemplazar la sombría solemnidad de los interiores barrocos, dominados por el contraste del negro con rojos y verdes profundos. En los revestimientos textiles, las diferencias entre los colores más luminosos del repertorio no obedecen únicamente a gradaciones tonales, sino también a cualidades añadidas como el brillo, que depende del tejido empleado, algo que podemos comprobar en relación al perla y el nácar, dos de los colores de mayor éxito. Identificado por Terreros con el gris de perle francés, el "color de perla" podía percibirse, según el tipo de tejido, como un gris extraordinariamente claro o bien como un blanco grisáceo e iridiscente ${ }^{20}$. En tapicería -para muebles y coches-y en lencería de casa o de criatura (amantadores), el perla vira hacia el blanco, gracias al uso preferente del raso o de los tejidos de seda de brillo, mientras que en las prendas de vestir masculinas, el gris oscurece debido al uso casi exclusivo de paños de lana. Por su parte, el "color de nácar" es un rosa muy claro que evoca los reflejos rosáceos de la madreperla. Todos los artículos textiles de color nácar fueron confeccionados en telas de seda con brillo. Por volumen encabezan la lista el raso y los brocados, seguidos a distancia por el espolín, la felpa, el tabí, el damasco, el tafetán (utilizado en forros de colchas), el mué, la persiana y la princesa, dos géneros, estos últimos, empleados solo en cubrepiés femeninos con bordados de cartolina. El color nácar, en época de Felipe V, fue profusamente utilizado en cintas de raso lisas, listadas o floreadas que se emplearon en el adorno de colgaduras de cama, cortinajes y espejos o cuadros colgados. El tercer puntal de este triunvirato de los fríos claros a la moda es el "color de porcelana" que, según el Diccionario de Autoridades, responde a un blanco mezclado de azul. Asociado a la idea del blanco puro, aparece en mobiliario ${ }^{21}$ y en prendas de vestir confeccionadas en tafetán o gloritú que, con el movimiento, favorecían los reflejos azulados. 
Si el perla, el nácar y el porcelana son tonos fríos que se alían con frecuencia al azul y al verde claro de molduras y muebles, el "color de leche" y el "color de lana" conforman las variedades cálidas del blanco. El primero aparece en envolturas infantiles y en prendas de vestir femeninas, siguiendo tal vez una asociación de ideas entre lactancia, feminidad e infancia que se materializa en la cultura material de mujeres y niños ${ }^{22}$. El "color de lana" se empleó únicamente en relación a mantos -y mantas- confeccionados con tejidos muy concretos, paños dieciochenos de Épila e Illueca ${ }^{23}$.

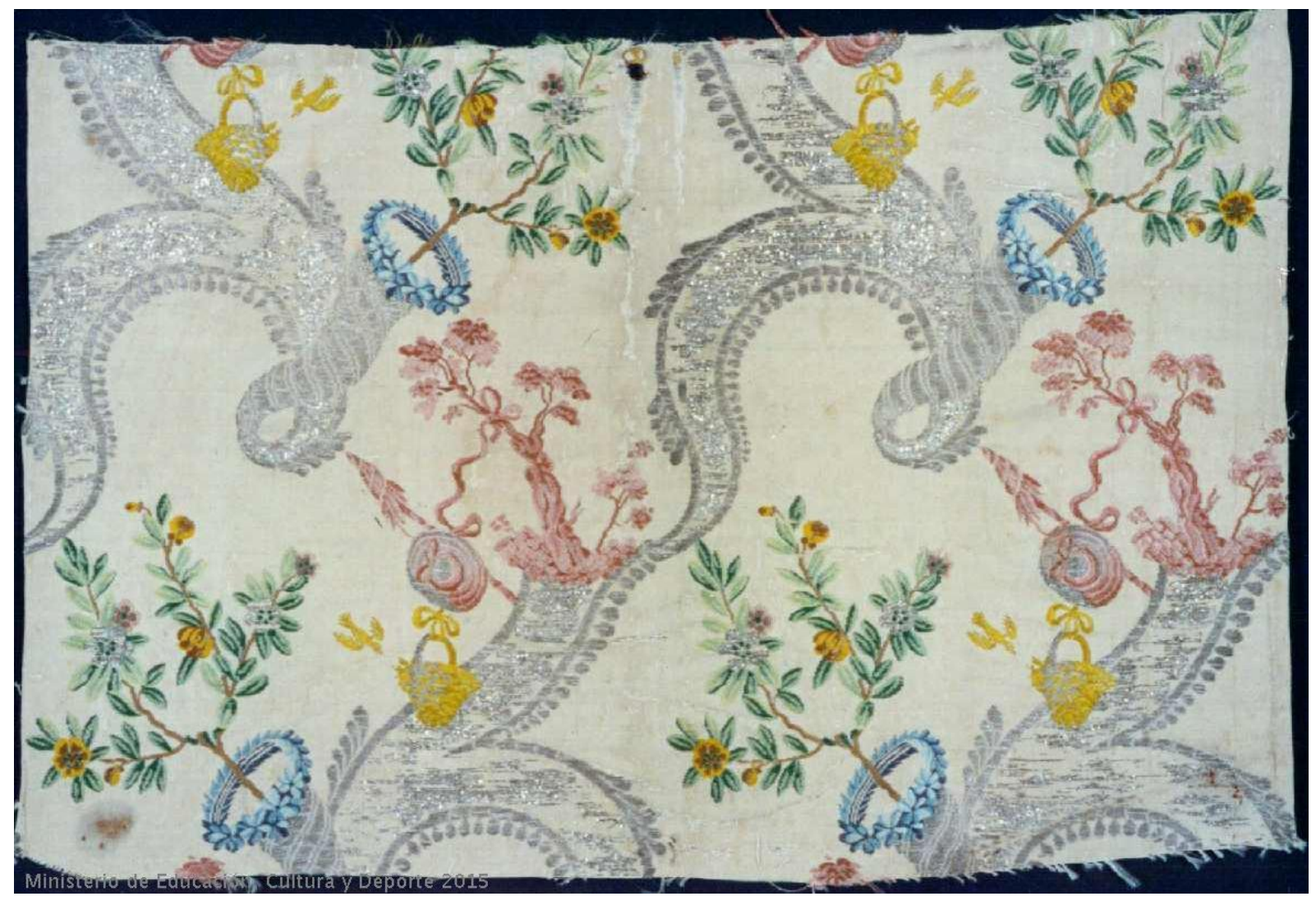

Fig. 2. Espolín de seda con fondo blanco porcelana y motivos decorativos en hilo de plata e hilos de seda en rosa, azul, amarillo y verde. Segundo o tercer cuarto del siglo XVIII. MNAD, inv. CE21440. El espolín rameado de oro o plata aparece empleado en la documentación consultada en colgaduras de cama completas o cobertores a partir de la década de los cuarenta. 


\section{De flores, limones y pájaros}

El amarillo es un color simple, primitivo o maestro con mala prensa a lo largo de la historia y que, en el Setecientos, parece desprenderse de malhadados simbolismos multiplicando su presencia y repertorio. Adquiere una tonalidad y nombre específicos en los cordobanes curtidos y adobados "al uso de Valencia", por el que se dicen "alimonados". Para Joseph Antonio Varcárcel este característico amarillo limón se obtenía al teñir los cueros de cabra con la simiente de espino negro ${ }^{24}$. No obstante, la fórmula más detallada de los cordobanes alimonados la encontramos en el Arte de Curtir de Cayetano Miguelez (1805), según la cual el tono se conseguía aplicando en la flor de la piel varias manos tinta de alazor, que es como llamaban en Castilla al cártamo o azafrán salvaje (carthamus tinctorius).

Un caso de especial interés es el del "color de Ysavela", un amarillo pálido con matices agrisados que irrumpe en los inventarios de época filipina para decaer a partir de 1745. El origen de la denominación "Ysavela" (ingl: isabella, isabellinel fr: isabelle) no está claro y en torno a su etimología circulan varias leyendas de dudosa veracidad y peor gusto. La más extendida hace alusión al aspecto que habría adquirido la camisa que la archiduquesa Isabel Clara Eugenia llevó, en cumplimiento de una promesa, durante los cuatro años que duró el Sitio de Ostende. La segunda versión, muy parecida, se limita a cambiar el nombre de la protagonista por el de Isabel de Castilla, y el acontecimiento en cuestión por el Sitio de Granada. El Oxford Dictionary desmiente ambas leyendas enarbolando una primera mención de la voz en un inventario del guardarropa de Isabel I, hecho en 160025. En cuanto a su aparición en los diccionarios de cronología moderna, la referencia fundamental al uso del color Isabelle en relación a la moda se la debemos a Antoine Furetière, quien, a finales del siglo XVII, afirmaba que les jupes isabelles ont été longtemps à la mode, parce que c'est une couleur douce ${ }^{26}$. El aprecio por el Isabela en la España de Felipe V puede interpretarse, por tanto, como consecuencia de la importación de una moda francesa. En Zaragoza aparece en conclusiones femeninas pero también en toallas de sobremesa y de almohada confeccionadas en tafetán que lucirían ese jaune bien lavé que tanto había gustado en La Francia de Luis XIV ${ }^{27}$. Curiosamente, el ysabela reaparecerá en documentos del fin de siglo, si bien solo en el ámbito de la indumentaria. A pesar de esta fulgurante resurrección, desde mediados del siglo XIX el color se desvinculará de los textiles para pasar a aplicarse al pelaje de los caballos. Desde entonces da nombre a un tipo de caballo, el Isabela, perteneciente al grupo de los pálidos, lo que favorece la confusión con los bayos, a pesar de los esfuerzos de los expertos por fijar las diferencias ${ }^{28}$. A causa, además, de los matices agrisados que pueden aparecer en su manto, hay clasificaciones que los asimilan a los perla 29 . El cúmulo de matizaciones recogidas en los libros en el siglo XIX, sugieren que el Ysavela había sido mucho más fácil de identificar en los fugaces años en los que ejerció su influencia en la indumentaria femenina.

En su tesis sobre las Cases Grans de Barcelona, Rosa Creixell se interrogaba sobre un enigmático "color d'aroma" que, sin embargo, no aparece en 
la documentación zaragozana. Se trata de un amarillo dorado característico de las flores del aromo, un tipo de acacia que en el siglo XVIII también recibía los nombres de aroma o copo, y que se utilizaba por entonces como árbol ornamental en los jardines domésticos ${ }^{30}$. La gran novedad entre los amarillos es el "color de canario". En Zaragoza aparece por primera vez en un inventario de 1796, etiquetando diferentes géneros textiles que se hallaron en el almacén y botiga de un mercader con importantes contactos comerciales en toda Europa ${ }^{31}$, circunstancia ésta que conviene resaltar ya que esta variante se utilizará en el vocabulario específico de las artes del tinte antes de recalar en el habla común, donde permanece hoy para designar a un amarillo intenso. Se obtenía a partir de una granilla de Tortosa (el rhamnus catharticus de Tournefort o el rhamnus infectorius de Linnéo) que venía a sustituir a la granilla de Aviñón y que, según Díaz de Valdés, "sirve muy bien para lograr este género de pajizo" 32.

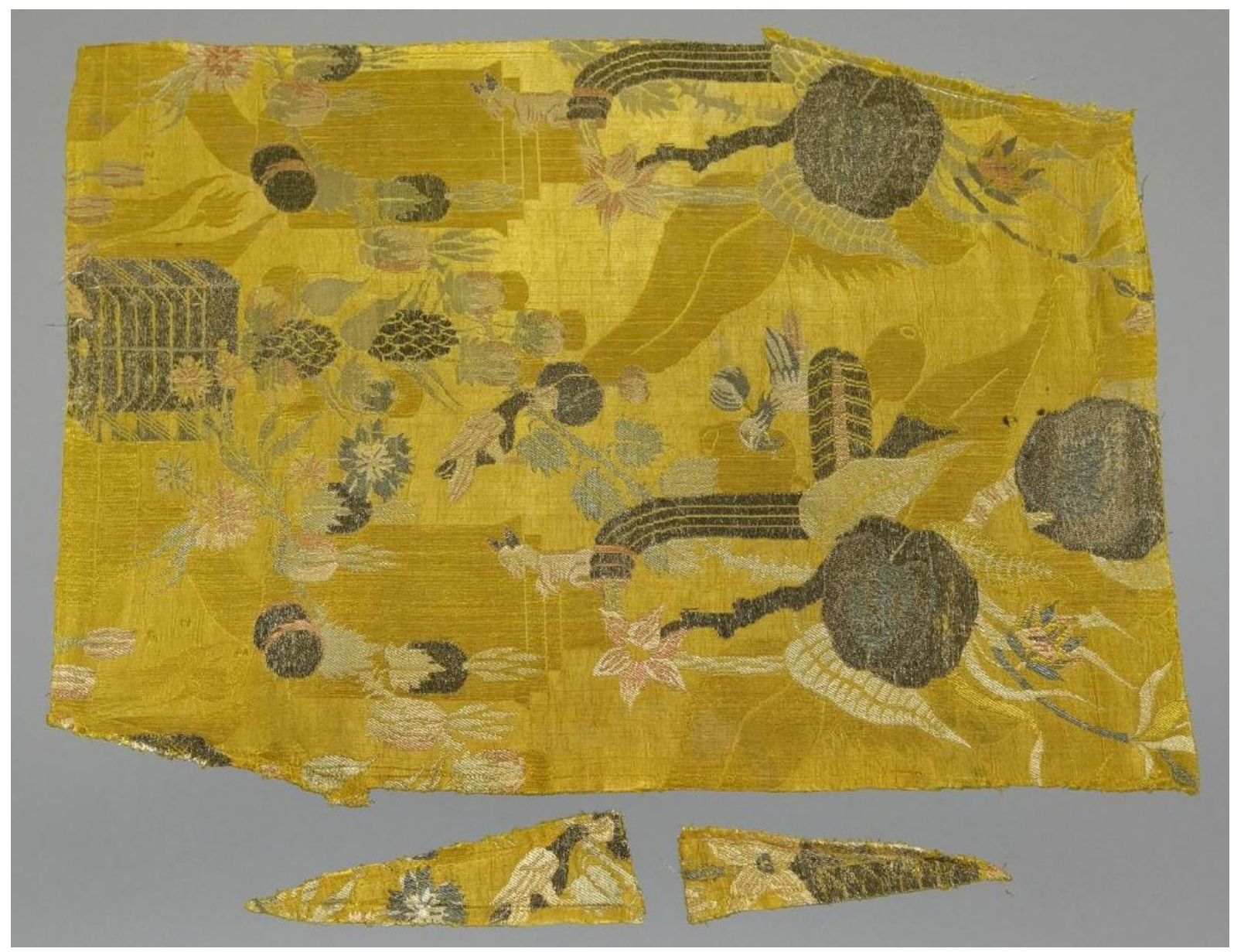

Fig. 3. Damasco de base amarilla con tramas espolinadas en beige, verde claro, blanco, azul, salmón e hilo metálico plateado. Se data entre 1695-1720, coincidiendo con la moda de las sedas bizarras. Su compleja confección se traduce visualmente en una gran riqueza de matices, logrando un efecto de conjunto en el que predominan los tonos amarillos, rubios, blanquecinos y también plateados y parduzcos. MNAD, inv. CE24522. 


\section{A medio camino. Rubios, tostados, anaranjados}

Algunos colores se sitúan en zonas fronterizas, a medio camino entre otros más claramente reconocibles. Así sucede, precisamente, con el pajizo que, por la gran cantidad de referencias, encabezaría la lista de los más utilizados en la decoración de interiores si no fuera porque casi nunca aparece en solitario, sino en combinación con otros, bien como fondo de motivos en resalte, bien en la confección de franjas. Al principio en contraste con colores maestros de saturación fuerte (rojo, verde, negro), más adelante con el azul y los pasteles. Mientras que el color de caña -empleado indistintamente en tejidos, mobiliario y coches ${ }^{33}$. oscila entre el beis y los tostados, el pajizo se suele presentar en las fuentes literarias de la época como un amarillo desvaído, algo bajado de tono. Así parece sugerirlo Antonio Ulloa al describir las mutaciones del sol en los cielos americanos: "parecían los arcos en figura oval ó elíptica correspondiente al disco del sol y después se perfeccionaba hasta quedar perfectamente circulares; cada uno de los pequeños constaba de encarnado ó rojo, este se desvanecía y formaba el naranjado, á quien seguía el amarillo y, desvanecido, se convertía después en pagizo"34. Esta concepción del pajizo como degradación tonal de un color intenso la subraya Terreros al comentar un uso particular del francés paillé, adjetivo que se usa para diagnosticar un defecto de los licores que, "habiendo de ser encarnados, están pajizos". El parentesco entre el amarillo y el pajizo queda más claro en la observación que recoge el lexicógrafo jesuita a continuación, por la que, "dejando aparte el caso de estos licores, en las demás cosas se puede decir jaune" 35 .

El "leonado" es un rubio oscuro que recuerda al pelaje del león o, en un símil menos favorecedor apuntado por el médico Méndez Nieto para describir la sangre corrompida, al "ladrillo molido desleído en agua" 36 . El adjetivo leonado se usó en relación a tejidos, cueros y, además, para referirse a las tonalidades acarameladas de la piedra jaspe. Tanto es así que la expresión "jaspe leonado" en relación a tableros de mesa y galanterías de escritorio- se adoptó para diferenciar este tipo de jaspe de otros con matices verdiazulados o multicolores. Se menciona de vez en cuando el "leonado oscuro", una gradación tonal en la antesala de los pardos. El leonado fue uno de los colores más utilizados en el siglo XVII, tanto en la indumentaria de lujo como en los revestimientos y complementos decorativos. De su prestigio habla la siguiente máxima, recogida en 1605 por Andrés de Rey de Artieda: "el color leonado descubre señorío, el leonado oscuro congoxa" 37 . En el siglo XVIII, el uso del término leonado retrocede a partir de los años cuarenta, al tiempo que comienzan a crecer las referencias a tejidos, maderas y cueros "anteados"38. Resulta muy difícil determinar si, por entonces, hubo diferencias claras entre un color y otro. Cabe la hipótesis de que el progresivo descenso de alusiones al leonado no se correspondiese necesariamente con un abandono del gusto por dicho color, sino con un simple cambio de terminología, por el que la voz "leonado" hubiese sido, en la práctica, reemplazada por la de "anteado" para referirse a la gama afín de colores, tanto en tejidos y cueros como también para ciertos tonos de madera vista. Actúa en favor 
de dicha hipótesis la coincidencia de los usos de ambos colores en los complementos textiles, concentrada en la confección de tapetes, toallas de sobremesa, rodacamas y paramentos de cama, donde forma las caídas o las franjas de adorno ${ }^{39}$. En cuanto a sus gradaciones tonales, al tratarse de un rubio oscuro, se consideraba que tendía al amarillo al aclararse, y al rojizo al oscurecerse. Así lo constata el uso que hace del adjetivo Juan José Delgado (1754) a la hora de explicar, para hacerlos comprensibles a los lectores españoles de su tiempo, los colores de los frutos y de las maderas exóticas de Filipinas ${ }^{40}$.

En 1792 aparece una solitaria mención al color de "escombra", relativa a un "vestido completo" traído desde París"1. La voz escombra significa en catalán escoba ${ }^{42}$, de forma que cabe pensar en un color parecido al del ramaje seco con el que se hacían las escobas o, si se prefiere, en el color de las ramas secas de la planta homónima, semejante a la retama ${ }^{43}$, con las que solía hacerse este utensilio doméstico en Castilla. El "color de oro", que no debemos confundir con los dorados de fino o basto, con las corladuras ni con los adornos realizados en hilo entorchado de oro, se utiliza en todos los casos para referirse a tejidos de brillo a base de seda con una tonalidad dorada, preferentemente el tafetán y el raso, empleados en prendas de vestir, cortinajes y toallas ornamentales de sobremesa o almohada. Al igual que el "color de pulga", el "color de oro" se puso de moda en la corte de Luis XVI, donde se consideraba de buen tono lucirlo en los días helados ${ }^{44}$.

Si avanzamos hacia los rojos, los tonos más cálidos del espectro, habremos de hacer antes una parada en los anaranjados. El "color de naranja" o "naranjado" fue el habitual de las mantas de cama. Los matices amarillentos del naranja se desdoblaron, no obstante, en el "color de ámbar" -un amarillo dorado que utiliza en sedas y bordados fundamentalmente- y en el "color yema de huevo", un intermedio entre el amarillo dorado y el color naranjado. El yema de huevo sería, más adelante, el distintivo del caballo bayo amarillo.

\section{Todos los colores del rojo}

El capítulo de los rojos es tan variado como difícil de perfilar. El rojo es, prácticamente en todas las civilizaciones, un color cargado de significados. Históricamente ha jugado un papel protagonista en la escenografía del poder, en la heráldica y en la liturgia religiosa. El solo hecho de hablar del "color rojo" es en sí mismo un pleonasmo, como recuerda Michel Pastoureau, pues tanto el latín coloratus como el español colorado significan, a un tiempo, rojo y dotado de color ${ }^{45}$. Así pues, la propia etimología del adjetivo colorado acusa la importancia que tuvo este color en el paisaje cotidiano. La riqueza de términos relacionados con el color rojo que observamos en los documentos es, hasta cierto punto, fruto de la herencia clásica. El humanista Antonio Telesio, en su De Coloribus Libellus (1528) rescató tan solo doce colores de entre la inmensa selva lexicográfica que había dejado tras de sí la cultura cromática grecolatina. De los doce tonos fundamentales, la mitad eran matices del rojo o mezclas conseguidas a partir de aquel: ferrugineus (ruggine), rufus (rosso chiaro), roseus (rosa), ruber (rosso), 
puniceus (rosso fenicio) y fulvus (giallo-rosso) ${ }^{46}$. En la documentación zaragozana y en la barcelonesa recuperada por Creixell, aparecen una decena de términos distintos utilizados en el lenguaje común en relación al rojo o sus mezclas, excluyendo el carmín o el bermellón, que jamás utilizaron los escribanos a no ser que inventariasen los colores del taller de un artista.

El Diccionario de Autoridades consideraba sinónimos los términos colorado, encarnado y roxo, si bien este último tiene una segunda acepción como sinónimo de rubio que aún hoy se usa en la zona astur-leonesa ${ }^{47}$. Tampoco parece que haya distinciones entre rojo, colorado y encarnado en los inventarios. Como demostración baste comparar las numerosísimas sillas de baqueta de Moscovia, omnipresentes en la primera mitad de siglo, registradas indistintamente de las tres formas. Los cueros rojos trabajados a la manera de Moscovia se teñían con una decocción de palo de Brasil como recoge en el Arte de curtir de Cayetano Miguélez $^{48}$. Terreros tampoco hace especiales esfuerzos por diferenciar el colorado del rojo o el encarnado, aunque se decanta por reconocer un carácter genérico e inclusivo de todas las variantes tonales a la voz "colorado", que define simplemente como "lo que está encendido, de color rojo y mui parecido al fuego, como la sangre, el rubí, la grana, escarlata etc." 49

Si entre colorados y encarnados no se suele hacer diferencias, sí que se remarcan en el caso del "carmesí", un rojo intenso equivalente, por sus características y composición (a base de polvo de kermes vermilio), al carmín de pintores e iluminadores. En todos los diccionarios modernos se lo considera un color excelente y duradero. Que el carmesí era, a primera vista, distinto de los otros rojos empleados en las artes textiles se aprecia en el cuidado que ponían los escribanos en distinguir, siempre, entre terciopelo encarnado y carmesí. El Diccionario de Autoridades lo definió como un "color purpúreo mui subido, semejante al de la rosa castellana, que se da a la tintura de la grana, que sale en polvo de cierto gusanillo que se cría dentro de ella, el qual se llama en arábigo Karme" 50 . El carmesí quedó firmemente asociado a ciertos tejidos de seda de alta gama como el chamelote de aguas de la indumentaria cardenalicia y el damasco. Junto a brocados y terciopelos, el damasco carmesí formó la tríada de los tejidos suntuarios por excelencia en la decoración de interiores, donde se prodigó en cortinajes, tapetes, colgaduras de cama, a veces con arrimadillos a juego. Mantuvo su hegemonía entre los textiles de lujo buena parte de la Edad Moderna hasta que, en el siglo XVIII, comenzaron a ganar terreno los damascos azules y verdes.

El tinte de polvo de cochinilla en una sola aplicación (pues con dos baños alcanzaba el tono púrpura) es lo que distinguía igualmente al "color de grana". Es el rojo característico del tejido homónimo, un paño fino de lana que también se conocía como "polvo de grana" en el seiscientos y que, en el peor de los casos, debía superar la calidad de un paño dieciocheno. La misma coloración recibía la media grana, un tejido del mismo tipo que la sarga pero de calidad muy superior ${ }^{51}$. Las piezas confeccionadas en grana se concentran en los documentos de primera mitad de siglo y suele tratarse de prendas de vestir (dengues para ellas, capotes, capas y capotillos para ellos) o de paramentos completos de cama, 
embellecidos siempre por cenefas de terciopelo carmesí para buscar el contraste entre su opacidad y el brillo del vellutado de seda. El "color de cirera", es decir, de cereza, no se encuentra en las fuentes zaragozanas, pero se podría asimilar a los guindas de los muebles y objetos charolados (sillas, azafates, espejos de tocador) aunque en la documentación a los charoles rojos se les llama siempre encarnados. El "color de rosa" solo aparece en la indumentaria (batas de tafetán, casacas de griseta) al igual que el "color de fuego", sugerente denominación que ha quedado para describir el pelaje del caballo alazán, caracterizado por su capa simple con pelos color de fuego, una combinación -que no una mezcla- del rojo y amarillo.

Como el color de fuego, el "color de vinagre" hace su aparición en unas medias de hombre, y se convierte en uno de los tonos de moda en la España de Carlos IV, aunque rara vez fuera del ámbito de la indumentaria ${ }^{52}$. Por los mismos años irrumpe el "color sangre de toro" que luce una mampara de puerta ${ }^{53}$. En fuentes españolas e hispanoamericanas este rojo purpúreo, oscuro y brillante se utiliza para identificar la coloración de ciertos tejidos ${ }^{54}$ si bien la referencia original, sang de boeuf (sangre de buey), se refiere específicamente a un tipo de barniz a base de cobre empleado en la decoración de piezas de porcelana ${ }^{55}$. Chevreul, no obstante, identificaría en 1855 el sang de bouef con el "escarlata de Venecia"56 de mediados del siglo XVIII, lo que concordaría con el sentido que le se da en las fuentes hispanoamericanas modernas, como tintura de tejidos ${ }^{57}$.

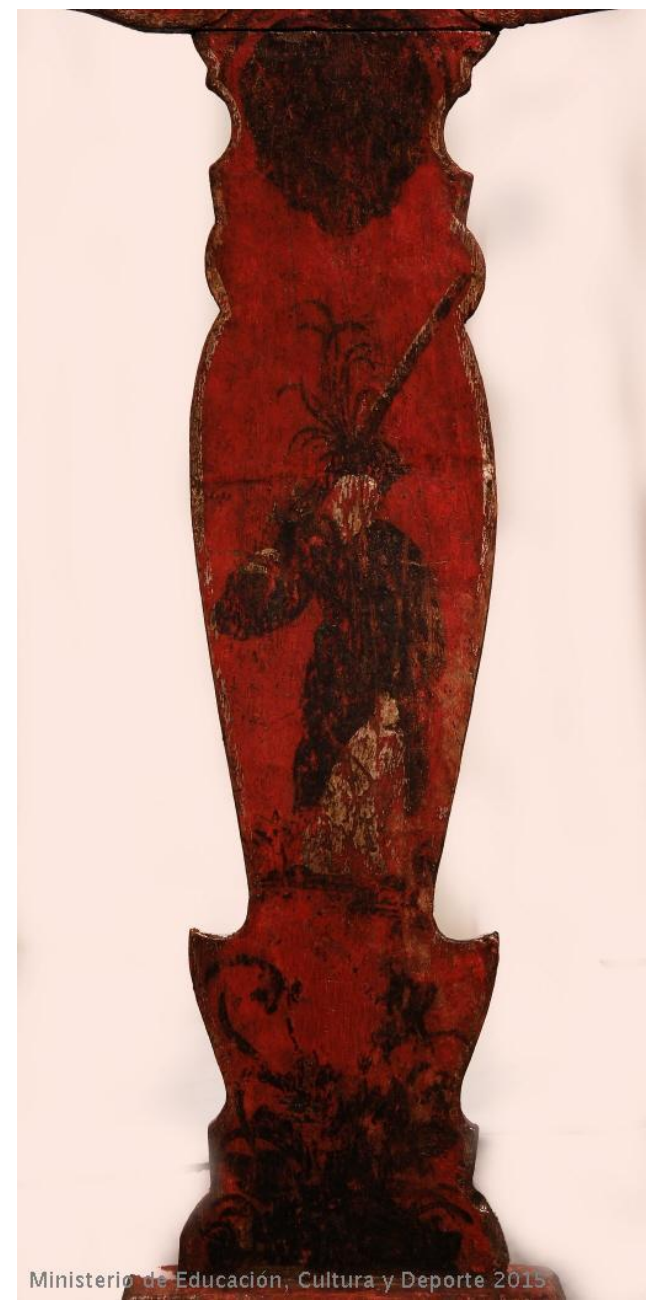

Fig. 4. Detalle de la pala central de una silla a la inglesa lacada y decorada con motivos de chinerías. 1751-1800. MNAD, inv. CE04009. Se trata de una muestra representativa de los "charoles encarnados" que aparecen en los inventarios. 


\section{Aceitunas y botellas}

A pesar de ser uno de los colores de moda, tanto en la decoración de los interiores como en la pintura de fachadas ${ }^{58}$, el verde se presenta en la documentación notarial en muy pocas variantes, el verde botella y el aceitunado en dos tonalidades, un aceituna claro y otro oscuro con el aspecto de un gris verdoso. El "verde botella" 59 aparece en el cambio de siglo, en prendas de vestir, al tiempo en que las botellas de vidrio se convierten en un objeto común, sustituyendo a otros contenedores de bebidas en los hogares ${ }^{60}$. El aceitunado oscuro se obtenía a partir de la mezcla de dos colores maestros, el azul y el amusco ${ }^{61}$. Así se procedía en la Real Fábrica de Tapices para los "matices" necesarios para los paños de verduras o boscaje. El aceituna claro, que encontramos siempre en colgaduras y cortinas de tafetán, encajaría en la gama de los pasteles de gusto rococó.

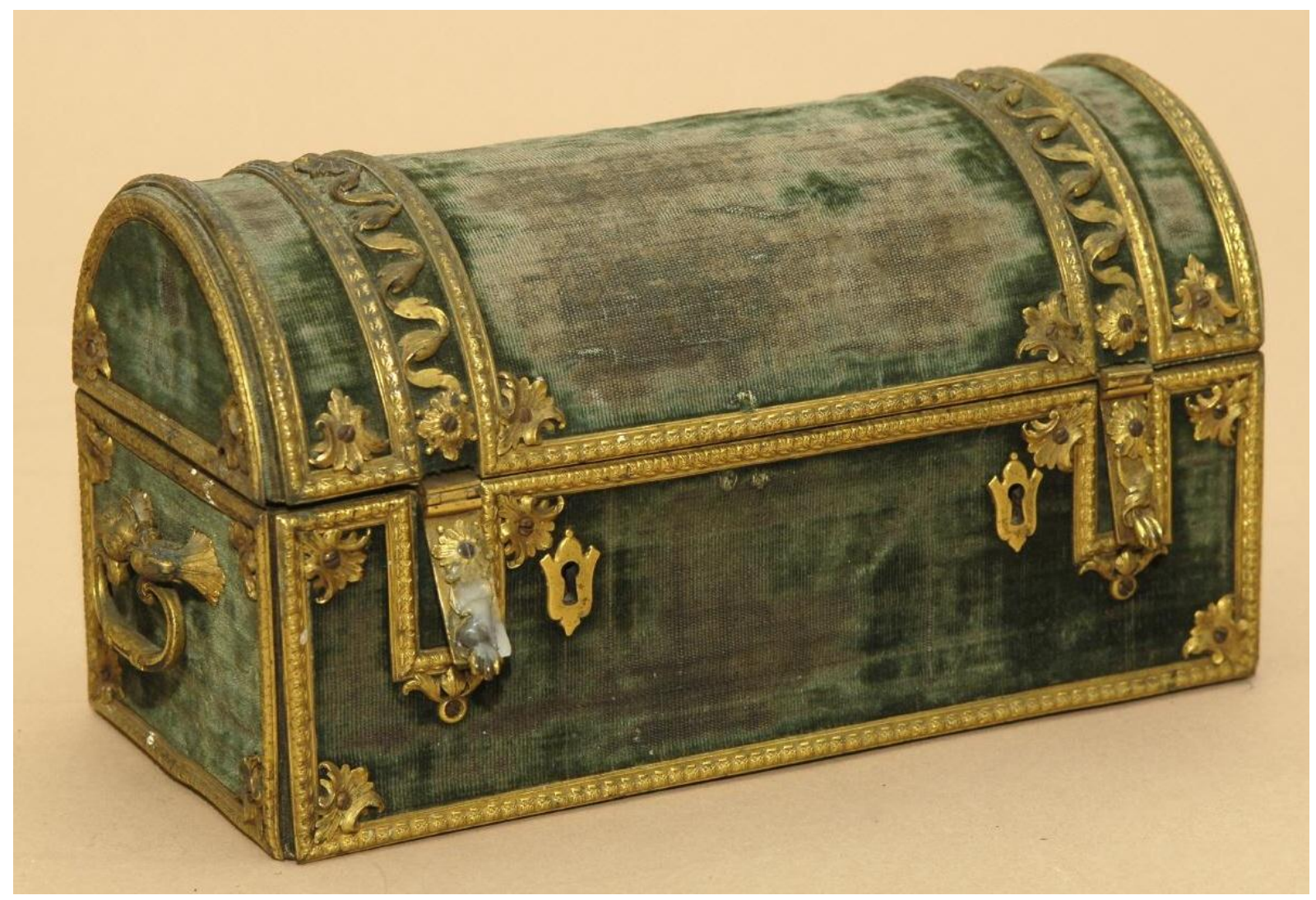

Fig. 5. Arqueta de tapa tumbada ensayalada en terciopelo verde botella y guarnición de metal dorado de molido. Siglo XVIII, origen europeo. MNAD, inv.CE27458. El tejido se encuentra deteriorado pero conserva zonas donde se aprecia claramente la coloración. 
El verde es uno de los colores dominantes en los interiores a lo largo de todo el siglo. En la primera mitad se alía con el negro de las maderas ebonizadas $y$, a menudo, en contraste con el rojo, sin que sea raro encontrarlos formando parte de una sola colgadura de cama. En tejidos económicos predomina el cordellate para cobertores, y la bayeta para cortinas de puerta y paramentos de cama, mientras que entre los géneros ricos de seda el tejido dominante es el damasco para cortinas, doseles y paramentos de cama. A partir de los años cuarenta el reinado del verde se extiende al mobiliario ${ }^{62}$. Sillerías, canapés, mesas de arrimo y rinconeras a juego con las cenefas de puerta, ventana o balcón de la misma estancia se pintan de verde claro (o del verdegay de los diccionarios) con sus correspondientes filetes dorados. Con voluntad de unificar los ambientes mediante el color, las molduras de los arrimadillos y las enmarcaciones de láminas y estampas siguen esta opción. Las camas de bancos -especialmente las de bancos de pie de gallo- con su correspondiente cabecero torneado o recortado, que desplazan a las camas de pilares a partir de los sesenta, se darán de verde en casi todos los casos. De hecho, aunque en el último cuarto de siglo el azul se imponga en sillerías, rinconeras y canapés, el mobiliario del dormitorio seguirá fiel al verde, lo mismo que en el caso de los catres -en su mayoría camas de díaque aparecen en el cambio de siglo y la primera década del ochocientos.

\section{El siglo azul}

Al igual que sucede con el color verde, el azul, declarado el color del siglo XVIII, presenta un vocabulario bastante escueto en las fuentes -limitado a "azul" y "zeleste" -, que se amplía poco más cuando se acude a los diccionarios de época que aportan, por ejemplo, el azul oscuro o "turquí", también conocido como añil 63 . Aunque las fuentes aragonesas y catalanas registran el morado -vinculado al filipichín, que se emplea en la confección de mamparas de puerta- existe un vacío entre éste y el azul que debería estar ocupado por los violáceos. Uno de los colores que se situaría dentro de este paréntesis sería el "flor de romaní" de las fuentes barcelonesas, o color flor de romero, sin equivalencia en los inventarios aragoneses. En los inventarios, el "azul celeste" parece aplicado solamente a piezas de seda, cortinas y doseles, con el damasco como tejido de calidad superior, al que siguen el tafetán y el mué, empleado puntualmente para ensayalar exquisitas cajas de tocador64. La expresión "azul de nubes", aplicada inusualmente a la caja de un coche, podría ser una forma de referirse al celeste o, por el contrario, podría estar relacionada con las características de ciertos tejidos que aparecen, de forma recurrente, en colgaduras y revestimientos: el tafetán de nubes -en algunos interiores de los cuarenta- y el cotón de nubes, muy utilizado en el último cuarto de siglo, sobre todo en cortinas y cubiertas de asiento. En la confección de revestimientos y guarniciones textiles, la alianza del azul se consuma preferente con el nácar, el perla y el pajizo, tanto en lo que toca a los interiores como en la guarnición de berlinas y cupés. 


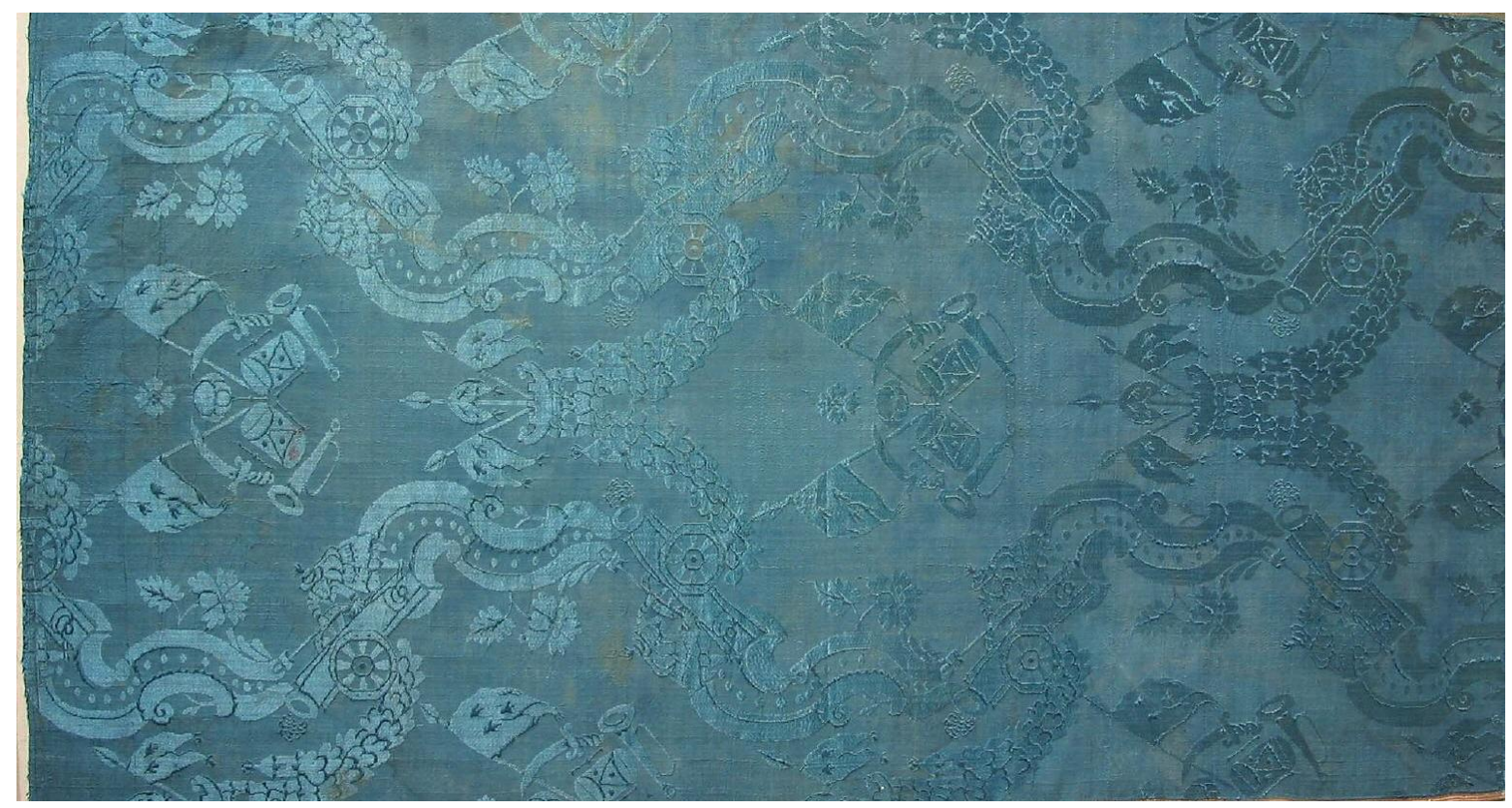

Fig.6. Damasco azul con motivos figurativos en raso sobre un fondo con ligamento de tafetán. Primera mitad del siglo XVIII. MNAD, inv.CE21426. El damasco azul se utiliza en los interiores zaragozanos, principalmente en cortinajes, colgaduras, cenefas y cubiertas de muebles a partir de los años cuarenta, socavando la hegemonía del carmesí en los complementos de damasco.

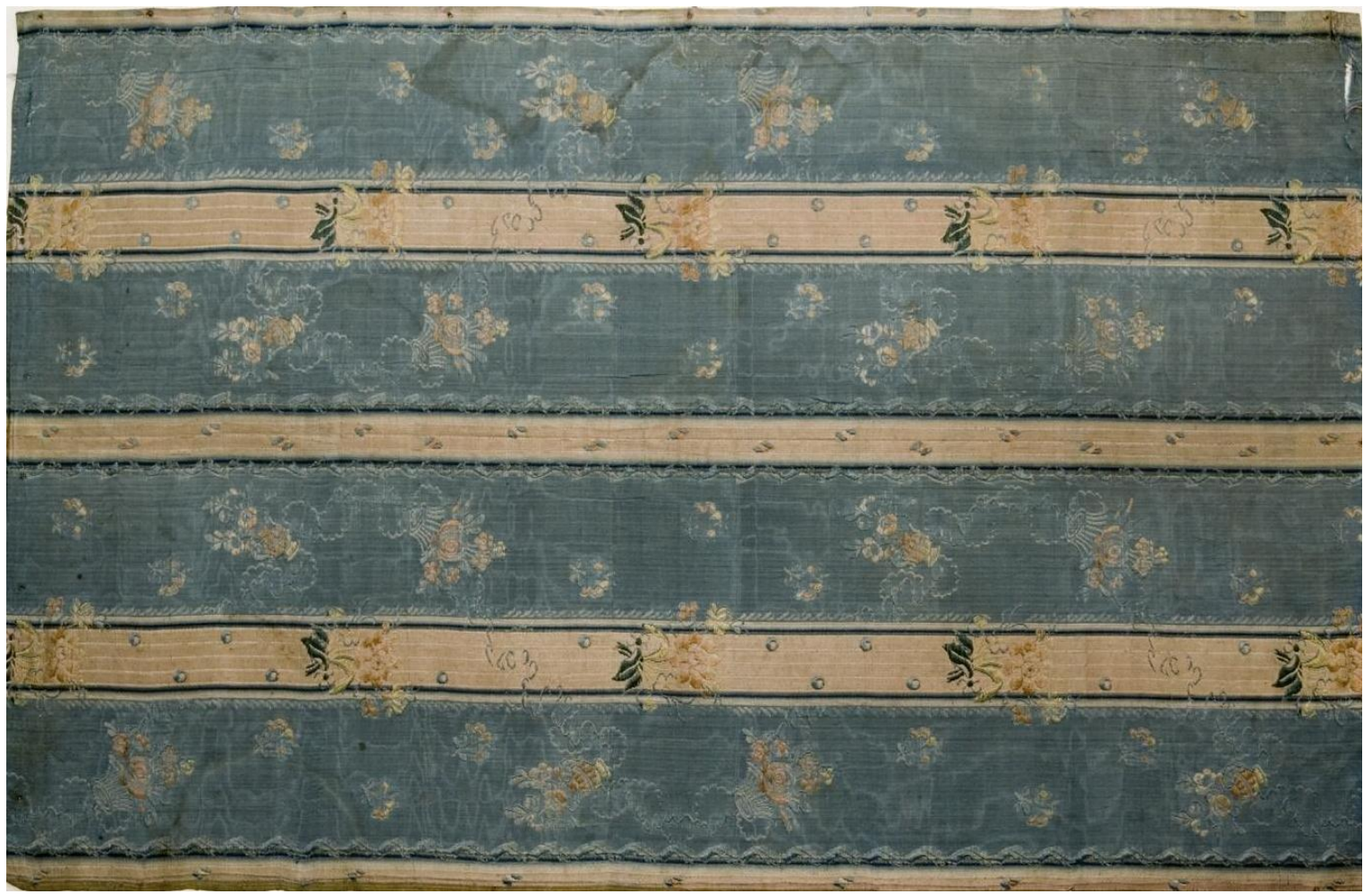

Fig.7. Tafetán listado en alternancia de azules y tonos claros. Segunda mitad del siglo XVIII. MNAD, inv. CE21456. El fondo es de tafetán azul con terminación de moaré, lo que nos permite sugerir que puede tratarse del tejido denominado llamado "tafetán de nubes" en las fuentes notariales aragonesas, un género textil profusamente utilizado en tapicerías y colgaduras en el último tercio de siglo. 
El gusto por los tejidos listados en época de Carlos III y Carlos IV favorece la combinación del blanco y el azul, un diseño hasta entonces distintivo de géneros ordinarios de uso funcional (lienzo "varetiado" de Flandes) ${ }^{65}$ que pasa ahora a los tejidos de moda con uso decorativo como el cotón 66 .

Como sucede con el verde, el azul cobrará un protagonismo especial en el mueble pintado, esta vez en la década de los sesenta, consolidándose la tendencia en lo que queda de siglo ${ }^{67}$. Hay viviendas enteras decoradas con mobiliario dado de azul, siempre con sus dorados de fino, de basto o de corladura, un acabado que se extiende a las molduras de los adornos de pared, en media caña, a las cenefas de sobrepuerta y a las arañas de madera68. Los complementos textiles a este mobiliario -cortinas, cubiertas y sobrecubiertas para los muebles de asientoproponen un juego de fríos al unirse al celeste, al verde o a los claros de moda ${ }^{69}$. Pero, junto a esta opción, pervive todavía el gusto por las combinaciones contrastadas, yuxtaponiendo el azul de muebles y molduras con tejidos carmesíes o bien, en sentido opuesto, el rojo de los muebles charolados con tejidos azules o azules y blancos (cotón fundamentalmente) ${ }^{70}$. En cierto modo, es como si el nuevo dúo de azul y rojo intensos viniese a sustituir al verde subido de tono en su longevo maridaje con el rojo. El retrato póstumo de Martín Funes y Lafiguera, pintado por Luis Muñoz Lafuente en 1791, podría servirnos -con su mezcla de carmín, azul y verdemar- para ilustrar el gusto por esta peculiar combinatoria ${ }^{71}$. En los interiores decorados de este modo podemos apreciar lo que Pastoureau describiría como la vigencia de una sensibilidad cromática muy diferente a la nuestra, que no tiene por inarmónicas combinaciones que hoy nos resultan estridentes. Lo que el investigador del color percibió como una constante histórica -consecuencia de la consideración del color como un producto cultural- queda perfectamente expresado en la vieja máxima latina de coloribus et de gustibus non est disputandum. 


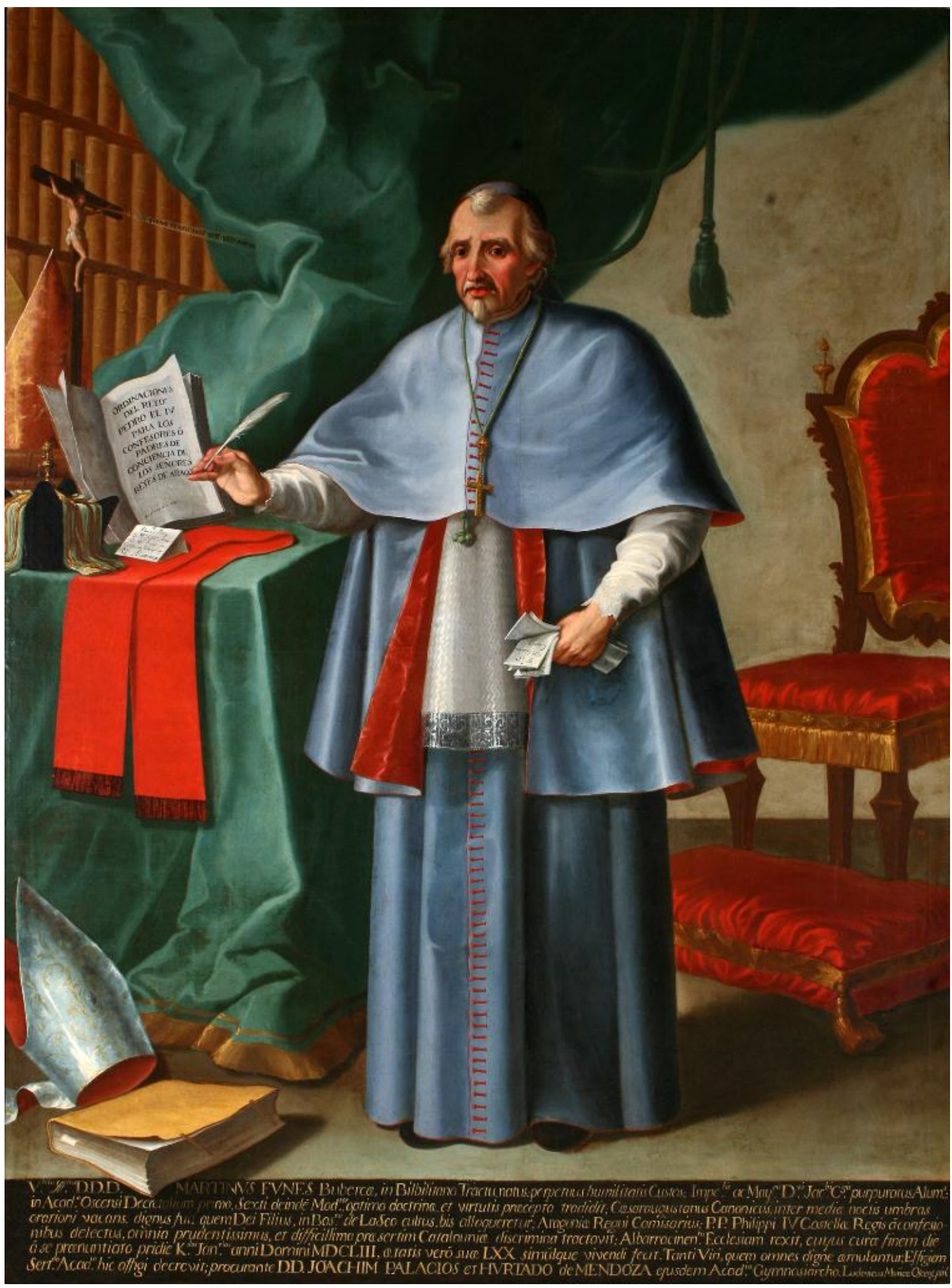

Fig. 8. Retrato de Martín Funes y Lafiguera (muerto en 1654). Óleo sobre lienzo pintado por Luis Muñoz Lafuente, en 1791, para el Paraninfo de la Universidad Sertoriana de Huesca. Museo de Huesca, fotografía de Fernando Alvira, inv. 03571. La imagen es representativa de la pervivencia del gusto por la combinación de colores intensos, especialmente el rojo, el verde y el azul. 


\section{Gris oscuro, casi negro}

Concluimos este recorrido con el que fuera, en la modernidad temprana, el color del lujo, la gravedad y la rectitud moral (gravitas, dignitas), especialmente cuando se materializaba en tejidos de especial brillo y profundidad. En la decoración de los interiores zaragozanos, el negro se acantonó en los cofres encorados de cordobán, en los escritorios y escaparates, en pequeños objetos lacados y en las molduras ebonizadas. En estos casos, el negro refleja tanto un fenómeno de sedimentación decorativa -la presencia de piezas antiguas- como la pervivencia de un gusto conservador que seguía apegado a formas y modelos antiguos, considerados de prestigio. El negro rara vez surge en textiles que no sean de vestir, a excepción de algunos cobertores de cama de felpa o bien de doseles del mismo tejido con los que resaltar crucifijos de pared, relicarios o benditeras ${ }^{72}$. Hay algunas referencias a diseños en bandas negras y blancas, en un cobertor de felpa y para arrimadillos de estera ${ }^{73}$ que también se localizaron en Barcelona, lo que permite suponer que se trata, como apuntó Creixell, de un modelo comercialmente tipificado ${ }^{74}$. La expresión "color de ébano" se utiliza para identificar las piezas en madera ebonizada, escaparates, escritorios, y las camas de peral con pilares salomónicos de los interiores de primera mitad de siglo ${ }^{75}$. Esta técnica imitativa domina también en enmarcaciones y molduras de peral teñido que repiten tipos de moda antigua, marcos ochavados para los espejos o marcos rizados en ajedrezados y ondas al estilo de los modelos barrocos de origen flamenco. Con una voluntad unificadora se daban de negro los bufetes y mesas de arrimo que servían de pie para los escritorios del mismo color, modelos al gusto del momento como los escritorios de ébano y concha o los de estilo napolitano, con gavetas revestidas de cristales pintados.

Aunque hoy nos pueda resultar extraño, el gris se tenía por un color a medio camino entre el azul y el pardo, como se refleja en el Diccionario de Autoridades, que en esto sigue a Covarrubias en una de sus disparatadas etimologías ${ }^{76}$. Sin embargo, a medida que avanzaba el siglo XVIII, de la mano de los estilos rococó y neoclásico se desarrollaría un gusto por los tonos medios que benefició a colores antes relegados, entre ellos el gris, que vería ampliada su familia en nuevas tonalidades con nombre propio. El rococó gustaría de la ligereza de los grises de saturación débil como perlas, cenizas y platas, resaltados con adornos de oro, mientras que el neoclásico estimaría su sobriedad. El "color de plomo", empleado en tejidos invernales como el terciopelo y la serpentina de lana, era un gris oscuro levísimamente azulado. El "color cendra", como "color de ceniza", llega tardíamente a la documentación zaragozana, a pesar de estar de moda durante la segunda mitad de la centuria ${ }^{77}$. Algo parecido sucede con el "pel de rata", un ceniza muy oscuro, casi negro, que se cita como "piel de rata"78. Una vez más, el lenguaje empleado para distinguir las razas de caballo rescataría la denominación para designar los matices cenicientos del tipo ratonero o tordo ratón ${ }^{79}$. 


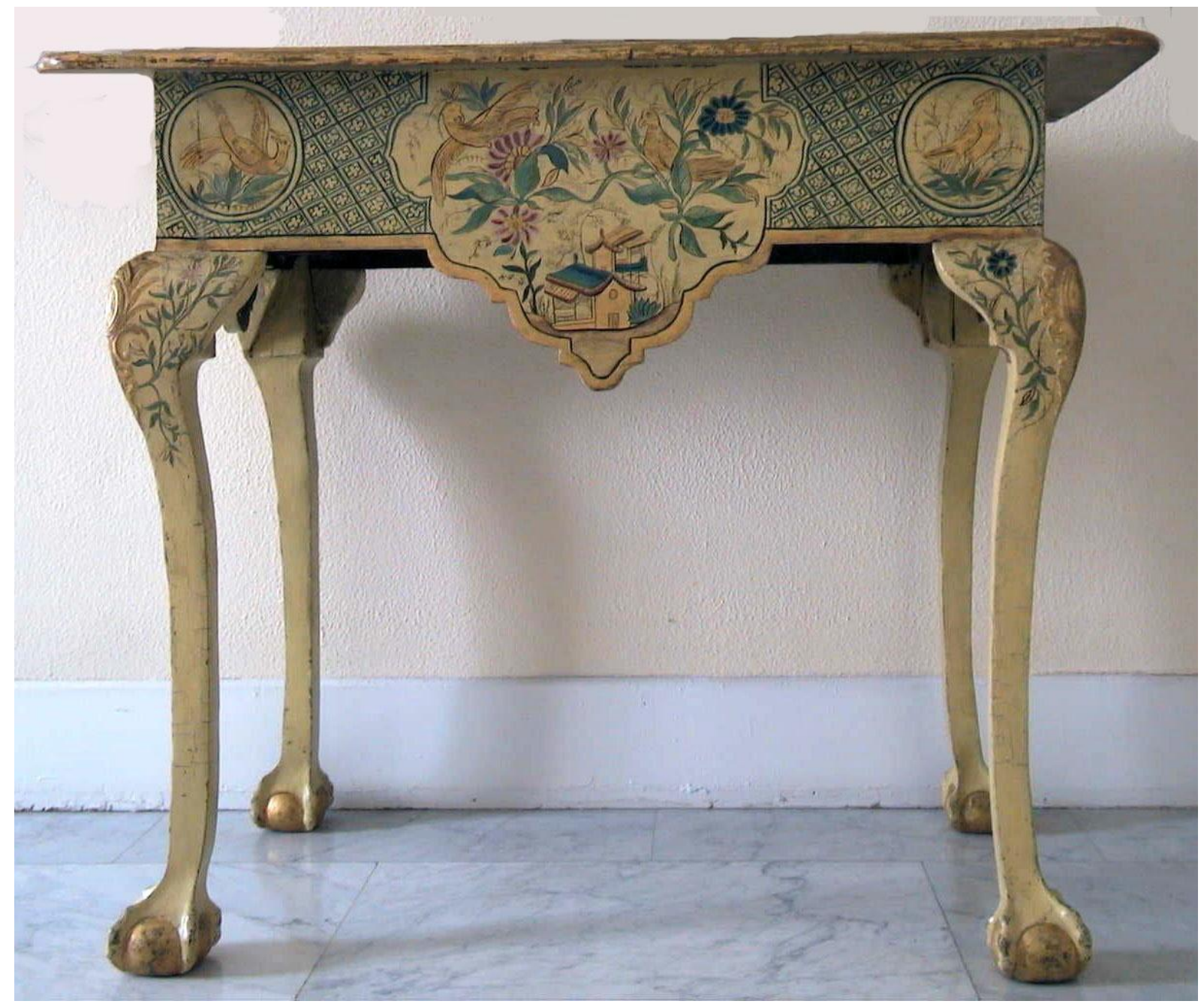

Fig. 9. Mesa auxiliar con faldón recortado y decorado con motivos de chinerías y patas con pie claw and ball. Catalogado como un ejemplar de mobiliario popular de origen levantino, está datado entre el segundo y tercer cuarto del siglo XVIII. MNAD, inv. CE05143. Los motivos en tonos azules, verdes y rojos un tanto fríos y no demasiado saturados se pintan sobre el fondo de charol en un tono amarillo sumamente pálido y cercano al beige, que nos haría pensar en una gama de colores que oscila entre el caña y el pajizo.

\section{Conclusión}

Durante siglos, los nombres dados a las gradaciones y mezclas de colores básicos se concibieron como evocación metafórica, designándose por su semejanza a objetos, sustancias, materiales o fenómenos perceptibles en la realidad circundante. Este vocabulario convivía con otro especializado, de carácter profesional. Si la documentación gremial o los manuales son imprescindibles para la recuperación del léxico científico-técnico, los inventarios se revelan como fuentes especialmente útiles para conocer su significado cultural a través de los términos utilizados en el habla común. Perfumes, bebidas y sustancias estimulantes de moda, cuyo consumo se asociaba a nuevas formas de sociabilidad que tenían lugar en el espacio doméstico, sirvieron con frecuencia como referente cromático. Otras veces, la denominación remitía a una anécdota curiosa, lo que 
podía resultar un reclamo comercial lo suficientemente persuasivo como para detenerse a apreciar el color de una rata, el de la ceniza o el de las pulgas. No es casual, por tanto, que la documentación más rica en este repertorio la constituyan los inventarios de mercaderes de artículos de moda, especialmente cuando se trata de tejidos. Para estos se acuñaron las denominaciones más sugestivas, que terminarían extendiéndose a la carpintería del mobiliario y de los coches. La diversificación de las denominaciones obedecía, al menos indirectamente, a estrategias mercantiles propias de un siglo en el que la moda, y la continua renovación que esta imponía, hicieron correr ríos de tinta. Los inventarios realizados por estancias nos permiten, además, apreciar ciertas pautas en el uso y combinaciones de los colores en la decoración. Las dos más importantes son, por un lado, su utilización como elemento unificador de los ambientes - con una progresiva querencia por los tonos fríos y claros- y, en convivencia con esto, una tenaz persistencia del gusto por las yuxtaposiciones de colores intensos, el tradicional rojo-verde y un pujante rojo-azul. En los interiores, como en la indumentaria y en los pinceles de quienes mejor reflejaron ciertas modas -el de Luis Paret y Alcazar, por ejemplo- los detalles se confiarán a los reflejos metálicos del oro y a los amarillos, tanto los dorados como los desvaídos.

\section{LISTADO DE COLORES EN LOS INVENTARIOS}

Marrones. Castaño, canela, clavillo, café, chocolate, tabaco, amusco/amuscado, color de hábito de San Francisco, color de hábito de Nuestra Señora del Carmen, color de granadillo, color de nogal, color de raíz de oliva, color de pulga. Tonos claros de moda. Perla, nácar (nacre), porcelana, color de leche, color de lana. Amarillo. Alimonado, Isabela, (color d'aroma), color de canario, pajizo. Rubios, tostados. Leonado, leonado oscuro, anteado, color de caña, color de escombra, color de oro, roxo. Naranja. Naranjado/color de naranja, color de ámbar, color yema de huevo. Rojos y sus mezclas. Colorado, encarnado, carmesí, color de grana, (color de cirera), color de rosa, color sangre de toro, color de vinagre. Verdes. Verde, verde botella, aceituna, aceituna claro, verde moscardón. Azul. Azul, azul celeste, azul de nubes, (turquí), morado, (flor de romaní), violado. Gris. Perla, plata, piel de rata, color de plomo/aplomado, color de ceniza (color de cendra). Negro. Negro, color de ébano.

\section{NOTAS}

\footnotetext{
${ }^{1}$ PLUCHE, Nöel-Antoine, Espectáculo de la Naturaleza o conversaciones a cerca de las particularidades de la historia natural, que han parecido mas a propósito para exercitar una curiosidad útil, y formarles la razón a los jóvenes lectores. Traducido al castellano por el P. Estevan de Terreros y Pando, Madrid, en la oficina de Gabriel Ramírez, 1771, VII, p.179.

${ }^{2}$ SARMIENTO, Martín, Sistema de adornos de escultura, interiores y exteriores, para el nuevo Real Palacio de Madrid: en que se representan para la elección de los mismos adornos, con descripción histórica, figuras sagradas, reales, científicas, militares, políticas y mitológicas: con una serie y cronología de todos los reyes de Esp, 1749. AGP, MSS/23038.
} 


\footnotetext{
${ }^{3}$ NIETO-GALÁN, Agustí, "La tecnología química: el caso de la tintura" en PESET, J. L. (dir.), Historia de la Ciencia y de la técnica en la Corona de Castilla, IV. Siglo XVIII, Salamanca, Junta de Castilla y León, 2002, pp. 631-651.

${ }^{4}$ VEGA, JESUSA, Ciencia, Arte e Ilusión en la España Ilustrada, Madrid, Consejo Superior de Investigaciones Científicas, p. 77.

${ }^{5}$ FERNÁNDEZ, Luis, Tratado Instructivo y Práctico sobre el arte de la tintura, Madrid, Imprenta de Blas Román, 1778, caps. IX y X. Citado por VEGA, Jesusa, Ciencia, Arte e Ilusión ...cit., p. 76.

${ }^{6}$ BAUDRILLARD, Jean, Le système des objets, Paris, Éditions Gallimard, 1968, pp. 42-51.

${ }^{7}$ GÓMEZ URDÁÑEZ, Carmen, Sobre el color en el acabado de la pintura histórica, Zaragoza, Prensas de la Universidad de Zaragoza, 2013.

${ }^{8}$ CREIXELL, Rosa $\mathrm{M}^{\mathrm{a}}$, Cases Grans. Interiors nobles a Barcelona (1739-1761), Tesis doctoral, Cap. VI, pp. 256 y 257.

${ }^{9}$ SANZ, Juan Carlos, y GALLEGO, Rosa, Diccionario Akal del color, Madrid, Akal, 2001.
}

${ }^{10} \mathrm{He}$ tratado la cuestión del papel de los revestimientos en varios trabajos precedentes. En particular, su relevancia como objeto suntuario en ABAD-ZARDOYA, Carmen, "La vivienda aragonesa de los siglos XVII y XVIII. Manifestaciones del lujo en la decoración de interiores" en Artigrama 19 (2004), Zaragoza, Departamento de Historia del Arte, 2005, pp. 409-425.

11 "Dos capotillos de grana con pieles color de castaña el uno, y el otro con caídas y ribetes color de castaña" A.H.P.Z., Joaquín Marín y Luna, 1804, ff. 85r.-89v.

${ }^{12}$ En el inventario del corredor Mariano Fornés y Árboles, un comerciante de artículos de última moda procedentes de Inglaterra, Francia, Holanda e Italia encontramos géneros textiles en todos los marrones de moda: canela, chocolate, tabaco y, sobre todo, clavillo. A.H.P.Z., Miguel Borau de Latras, 1796, ff. 101r.-113v.

${ }^{13}$ Los otros colores considerados maestros eran el encarnado, el azul, el pajizo y el negro. Véase VEGA, Jesusa, Ciencia, Arte e Ilusión..., cit., p.81.

${ }^{14}$ Uno de los coches de la condesa viuda de Torresecas combina la madera dada de amusco con la tapicería íntegramente confeccionada en terciopelo del mismo color. A.H.P.Z., A.H.P.Z, José Cristóbal Villlarreal, 1749, ff. $605 \mathrm{r}$.- $617 \mathrm{r}$.

${ }^{15}$ Una vez teñido el fondo se aplica una capa de aceite de linaza sobre la que se simulan, con ayuda de un pincel impregnado en una mezcla de aceite y sombra, las vetas o nudos de la madera. ORELLANA, Francisco Vicente, Tratado de barnices y charles enmendado, y añadido en esta segunda impression de muchas curiosidades y aumentado al fin con otro de miniatura, Valencia, Joseph García, 1755, pp. 94-95.

${ }^{16}$ Se trata de una moda concentrada en los años del reinado de Felipe V. Las descripciones remiten a un modelo que $\mathrm{M}^{\mathrm{a}}$ Paz Aguiló Alonso identifica con producciones sevillanas que no aparece en los inventarios españoles hasta el segundo tercio del siglo XVII. Encontramos ejemplares de granadillo auténtico en el inventario post mortem de don Antonio Piedrafita, hidalgo del Consejo de Su Majestad, A.H.P.Z., Pedro Joseph Andrés, 1703, ff. 124v.-128v, en el de don Manuel de Jaca, A.H.P.Z., Juan Antonio Loarre, 1709, ff. 251r.-252v. en el de don Antonio Manrique de Luna, A.H.P.Z., Juan Antonio Loarre, 1711, 54r.-59v y entre los bienes aportados por don Pedro Jordán de Urriés a su matrimonio con doña María Ana Piñateli y Rubí, A.H.P.Z., Esteban de Olóriz y Nadal, 1739, 137r.-146v. Las imitaciones color de granadillo pertenecieron al maestro platero Manuel de Villarrig, que aportó a su matrimonio en segundas nupcias con Ana María Adan, A.H.P.Z., Esteban de Olóriz y Nadal, y al maestro cubero Joseph Zurnaba, maestro cubero, A.H.P.Z., Joseph Domingo Assín, 1739, ff. 11r.$14 \mathrm{v}$.

${ }^{17}$ El procurador de la Real Audiencia don Antonio Lafiguera tenía varias mesas y todos los estantes para libros de su casa dados de color caoba. A.H.P.Z., Manuel Gil y Burillo, 1798, ff. 87r.-89r. En las casas que tenía en Zaragoza doña $\mathrm{M}^{\mathrm{a}}$ Francisca de Sales Portocarrero, dos veces Grande de España, en la anteoficina decorada con los retratos de sus ascendientes, hay dos armarios de pino color de caoba. AH.P.Z., Manuel Gil Burillo, 1798, ff. 231v.-233r. El canónigo don Faustino de Acha y Descartín, propietario de un moderno mobiliario, poseía numerosos muebles, incluidas calageras y un sofá, en color de caña y color de caoba. A.H.P.Z., Manuel Gil y Burillo, 1804, ff. 325v.-331v. El maestro peluquero Nicolás Xinobés el gran armario ropero. A.H.P.Z, Manuel Gil Burillo, 1800, ff. 110r. -11r.

${ }_{18}$ MOOREHEAD, Caroline, Bailando al borde del precipicio. Una vida en la Corte de María Antonieta, Madrid, Turner, 2010, p. 72. 
${ }^{19}$ El Procurador de la Real Audiencia don Antonio Lafiguera que tenía en su guardarropa un gran número de prendas de color vinagre - de moda en la época-, poseía también "una casaca y chupa de seda de color de pulga", A.H.P.Z., Manuel Gil y Burillo, 1798, ff. 87r.-89r.

${ }^{20}$ TERREROS Y PANDO, Esteban de, Diccionario Castellano con las voces de Ciencias y Artes, Madrid, Imprenta de la Viuda de Ibarra, hijos y compañía, voz "perla".

${ }^{21}$ La sillería completa en la casa de doña María García. El color porcelana armoniza con las cortinas azules alistadas de la habitación. A.H.P.Z., Pascual de Almerge, 1788, F.161V.-165V.

${ }^{22}$ Cubrepiés, tapapiés y paletinas. En lo que toca al ajuar infantil amantadores.

${ }^{23}$ El gremio de pelaires de Épila estaba especializado en la fabricación de paños dieciochenos y en Illueca había existido una importante producción de paños dieciochenos y golpeados que se vio muy mermada entre finales del XVII y principios del XVIII, como señala Ignacio de Asso. No obstante, Sempere y Guarinos constata, en la segunda mitad del setecientos, una milagrosa recuperación de los telares de esta segunda localidad, lo que explicaría el aumento de menciones del color de lana. SEMPERE Y GUARINOS, Juan, Ensayo de una biblioteca española de los mejores escritores del reinado de Carlos III, t. I, en Madrid, en la Imprenta Real, 1785 , p. 145 , nota a pie.

24 "Estando imprimiendo este tomo he sabido que la simiente, o granilla como dicen también del Espino negro [...] es excelente para teñir de pajizo: en Madrid la usan los libreros para dar este color a los pergaminos, y en Valencia los curtidores la emplean mucho para los cordobanes o pieles de color como alimonado, que es muy permanente" VARCÁRCEL, Joseph Antonio, Agricultura General y Gobierno de la Casa de Campo, t. IV, en Valencia, por Francisco Burguete, 1770, p. 226.

25 "One rounde gowne of Isabella-colour satten", Oxford English Dictionary, Oxford University Press, 2005. Además, véase Nichols, JoHn, (ed.) The Progresses and Public Processions of Queen Elizabeth III, London, John Nichols \& Son, 1823, voces Isabella e Isebelline p. 505.

${ }^{26}$ FURETIÈRE, Antoine, Dictionnaire universel, contenant generalement tous les mots françois ; et les termes des sciences et des arts / corrig. et augm. par M. Basnage de Beaval, et en cette nouve. édit. rev. et augm. par M. Brutel de la Riviere, La Haye, Chez Pierre Hullon, 1727.

${ }^{27}$ Además, el infanzón y maestro tafetanero Ypólito Juan Pomes, que almacenaba en su casa no pocos géneros de seda de nueva moda, incluía entre estos un rollo de trece varas de Ysabela. A.H.P.Z., Juan Antonio Loarre, 1718, ff. 1r.-5v. "una toalla de tafetán de color de Ysavela con puntas verdes y pajizas" de doña Josepha Moneba en A.H.P.Z., Juan Antonio Loarre, 1713, ff. 473r.-476v.

${ }^{28}$ En los inventarios la voz toalla se utiliza con cuatro significados diferentes que se corresponden con cuatro tipos objetos distintos: la toalla de manos, la toalla de comunión, la toalla de sobremesa y la toalla de cama. Si las dos primeras son de labor blanca, las restantes presentan una gran variedad de tejidos, labores ornamentales y guarniciones. La toalla de cama es una pieza ornamental que se coloca sobre las fundas de almohada. La toalla de sobremesa se diferencia del tapete porque no cubre enteramente el mueble sobre el que se coloca, ni se confecciona siguiendo su perfil y volúmenes de forma que no tiene "caídas" sino franjas o flocaduras.

29 "Hay tres especies de isabelas: el claro, el oscuro y el dorado. El Isabela claro es un amarillo blanquecino; el oscuro se parece al café con leche bastante teñido, y el dorado es un amarillo encendido y brillante." en VILLA Y MARTÍN, Santiago de la, Exterior de los principales animales domésticos y particularmente del caballo, Madrid, Establecimientos Tipográficos de M. Minuesa, 1881, p. 398. "Isabela ó perla.- Tambien es un reflejo amarillento el que caracteriza este pelo, en cuyo concepto guarda bastante semejanza, cuando no identidad absoluta, con el blanco amarillento y el café con leche" en Idem, p. 398. "Perla, perlino ó isabela.- Es un blanquizco ceniciento y deslustrado semejante al color de la perla; los hay claros y oscuros... Sería muy larga y algo difícil la tarea de manifestar la variedad de matices que presenta esta capa, desde el Isabela claro, que es casi blanco, hasta el isabela muy oscuro; que se asemeja al bronce, en HIDALGO Y TERRÓN, José, Obra completa de equitación, Madrid, Velasco, 1889, p. 208. "Perla, perlino ó Isabel. Capa del caballo que tiene el pelo de un color muy parecido al de la perla", en Ídem, p. 272.

${ }^{30}$ Diccionario de Autoridades. "Aromo. Árbol pequeño de corteza espinosa cuyas hojas se parten y dividen en otras pequeñas. Lleva la flor que en Sevilla se llana Aroma, y en otras partes de Andalucía copos", "Aroma. La flor del aromo es dorada, redonda y vellosa, y de olor muy fragante, con el pie largo como el de las cerezas, y del tamaño de una de ellas."

${ }^{31}$ Se trata de Mariano Fornés Y Árboles, A.H.P.Z., Miguel Borau de Latras, 1796, ff.101r.-113v. 
${ }^{32}$ DÍAZ DE VALDÉS, Pedro, Tratados sobre la física del clero y otros puntos útiles y provechosos de las Ciencias Naturales, impresos en el Memorial Literario de Madrid de 1787, 1789, 1790 y 1793, Barcelona, Oficina de Manuel Texero, 1806, p. 37.

${ }^{33}$ El conjunto más notable de muebles color de caña se encontró en las casas del presbítero y canónigo don Faustino Acha Descartín, quien tenía uno de los pocos sofás con asiento bombé colchado con crin de caballo que se citan en la documentación. A.H.P.Z., Manuel Gil y Burillo, 1804, ff. 325v.-331v.

${ }^{34}$ ULLOA, Antonio de, Viaje al reino del Perú (1748) citado por Andrés Saumell, en Historia 16, Madrid, 1990, edición digital, párrafo $\mathrm{n}^{\circ} 7$, página I, 547.

${ }^{35}$ TERREROS Y PANDO, Esteban de, Diccionario castellano...t. III, 1788, p.8.

36 "Llamo morir la sangre quando ya no sale biva, fina y encendida o colorada, como lo suele estar quando no está corronpida, sino que sale de color leonado o de ladrillo molido y desleydo en agua", MÉNDEZ NIETO, Juan, Discursos medicinales (1606-1611), edición de Luis E. Rodríguez San-Pedro, Salamanca, Universidad de Salamanca, 1989, p. 434.

${ }^{37}$ REY DE ARTIEDA, Andrés de, Discursos, epístolas y epigramas de Artemidoro, edición, prólogo y notas por Antonio Vilanova, Barcelona, Selecciones Bibliófilas, 1955, p. 95.

${ }^{38}$ RAE, Diccionario de Autoridades...cit., t. I, ““"anteado: especie de color dorado baxo, como el que tiene la piel de ante adobada de la que se toma".

${ }^{39} \mathrm{El}$ tapete de mesa es la funda confeccionada en la forma y perfiles del mueble que reviste, de manera que en los inventarios se suelen describir pormenorizadamente los materiales y adornos que se utilizan en las caídas del tapete. Para el caso de las toallas véase nota 29. El rodacama, que tapa las patas o los pies de los bancos de la cama, se ve por debajo del cobertor. En la documentación consultada recibe también los nombres de rodapié y delantecama, semejantes a las voces entornpeu, y avantllit de los documentos catalanes y mallorquines respectivamente.

40 "Entre cada una de las hojas, y pegada al cuerpo del árbol, en lo alto de él, aparecen las frutas, que son á modo de pequeñas calabazas. Cuando la fruta está madura, la cáscara toma un color anteado rojizo" "Nace el hanunúlsul cerca de las playas; no es de mucha elevación, pues sólo llega á tener tres ó cuatro brazas de alto, pero en cambio es muy grueso y corpulento, de excelente madera, muy fina, durable y á propósito para cualquier artefacto; es de un color amarillo subido que tira algo á anteado. Sacan de él tablones muy anchos, de los cuales se pueden formar mesas, escribanías, papelerías, y también grandes cajones y cajas, aunque para estos últimos destinos no sirve esta madera por ser dura y pesada. Recibe muy bien el hierro, y se labra primorosamente la escultura en ella: bruñéndola y alisándola convenientemente, saca un lustre muy brillante, parecido en todo al amarillo dorado", en DELGADO, Juan José, Historia general sacro-profana, política y natural de las islas del Poniente llamadas Filipinas, Manila, Juan Atayde, Impresor de El Eco de Filipinas, 1892, pp. 520 y 435 respectivamente.

${ }^{41}$ Inventario post mortem de don Pedro Manada, A.H.P.Z. Manuel Gil Burillo, 1792, ff. 5r.-11v.

42 D. y M., Diccionario catalán-castellano redactado en vista de cuantos se han publicado hasta el día, Barcelona, Agencia Médica Catalana, 1847, p. 396. "Escombra. inanoll de rame tas etc. per netejar la pols de térra. Escoba, la que servéix por netejar orináis. escobón.”. Aparece en el inventario de don Pedro Manada, con artículos en tonos de moda: perla, clavillo, verde botella, color de plata.A.H.P.Z. Manuel Gil Burillo, 1792, ff. 5r.-11v.

${ }^{43}$ RAE, Diccionario de Autoridades..., t. III, 1732, p. 563, segunda acepción de la voz escoba. "Se llama también una mata grande a manera de retama, del mismo color de que se hacen las escobas".

${ }^{44}$ MOOREHEAD, Caroline, Bailando al borde del precipicio. ..cit., 2010, p. 72.

${ }^{45}$ PASTOUREAU, Michel, Y SIMMONET, Dominique, Le petit libre des couleurs, Paris, Éditions du Panama, 2005 , p. 31.

${ }^{46}$ Citado por QUONDAM, Amedeo, Tutti i colori del nero. Moda e cultura del gentiluomo nel Rinascimento, Vicenza, Angello olla Editore, 2007, p.82.

${ }^{47}$ RAE, Diccionario de Autoridades...cit., t. V, 1737, p. 646 voz "roxo: se toma también por rubio, como el color del sol, u del oro".

${ }^{48}$ MIGUÉLEZ, Cayetano, Arte de Curtir o Instrucción General de curtidos, Madrid, Imprenta Real, 1805, p. 53.

${ }^{49}$ TERREROS Y PANDO, Esteban de, Diccionario castellano con las voces de ciencias y artes, t. I, Madrid, en la Imprenta de la Viuda de Ibarra, Hijos y Compañía, 1786, p. 463. 
${ }^{50}$ RAE, Diccionario de Autoridades. cit., t. I, p. 183.

${ }^{51}$ HERRERO GARCÍA, Miguel, Los tejidos en la época de los Austrias. Fragmentos de un diccionario, Madrid, Centro de Estudios Europa Hispánica, 2014, p. 160.

${ }^{52}$ En casa de doña Manuela Boyra una "cubierta de cama de tapicería de color de vinagre con tafetán verde", A.H.P.Z., Pascual de Almerge, 1790, ff. 77r.-86v.

53 Ídem.

54 "De espumilla de nanquín de color grana, carmesí, morado oscuro, celeste, ante, blanco, sangre de toro, caña, azul”, COMISIÓN PARA ESCRIBIR LA HISTORIA MARÍTIMA DEL PERÚ, Historia maritima del Peru: $t$. 1-2. La independencia, 1790 a 1826 ...p. 314.

${ }^{55}$ SANZ, Juan Carlos, y GALLEGO, Rosa, Diccionario Akal del color ...cit., p. 797.

${ }^{56}$ El tinte escarlata de Venecia fue muy apreciado por su estabilidad: "En Venecia se consumía mucho para la fijación de los colores sobre la lana y se llamaba escarlata de Venecia, la que no debe ser confundida con la escarlata por la cochinilla, que ha sido llamada escarlata de Gobelinos o de Holanda: En efecto, el color del kermes fijado por el alumbre y el tártaro es de un rojo moreno, que no tiene la viveza que caracteriza la escarlata de la cochinilla; pero la primera tiene la ventaja sobre la segunda de ser más sólida y de no ser manchada por el lodo ni por las aguas alcalinas o jabonosas." GIRARDIN, J., Lecciones de química elementar con figuras repartidas por el contexto, explicadas el domingo en la escuela municipal de Ruan, adicionadas por Don Francisco Carbonell y Font, t.II, Barcelona, José Matas y de Bodallés, 1841, p.529.

57 CHEVREUL, "Moyen de nommer et de définir les couleurs", Mémoires de l'Académie des sciences de l'Institut de France, t. 33, Paris, Imprimerie Impériale, 1861, p. 131.

${ }^{58}$ En 1786 se pintaron de verde las fachadas de varias casas de Zaragoza, la llamada Casa de la Cabra, entonces habitada por don José Dara, sita en la calle de Botigas Ondas, y la de don Simón Tarazona en el Coso. El cronista de la ciudad, don Faustino Casamayor y Ceballos afirmaba que se había hecho siguiendo la moda de Madrid. CASAMAYOR Y CEBALlOS, Faustino, Años políticos e históricos de las cosas particulares ocurridas en la Imperial y Augusta Ciudad de Zaragoza, tomo III (1786), Biblioteca General de la Universidad de Zaragoza, M-108, f. 191 r. y v.

59 "Un vestido completo de seda de grano color verde botella bordado de lentejuelas", en A.H.P.Z., Joaquín Marín y Luna, 1804, ff. 85r.-89v.

${ }^{60}$ Las botellas comienzan a menudear en los inventarios en el último cuarto de siglo sustituyendo a frascos y redomas en el servicio del vino. PITTE, Jean-Robert, La bouteille de vin. Histoire d'une révolution, Paris, Tallandier, 2013.

${ }^{61}$ VEGA, Jesusa, Ciencia, Arte e Ilusión..., cit., p. 81.

${ }^{62}$ El clímax del verde en el mobiliario se alcanza, algo más tarde, en la casa de don Francisco Palacio del Fago, abogado de los Reales Consejos. Si la inmensa mayoría de los muebles son dados de verde la novedad, con respecto a los cuarenta, es la preferencia por complementos textiles en azul o azul y blanco, en cotón listado y cotón de nubes, A.H.P.Z., José Antonio Ramírez y Lope, 1774, ff. 155r.-161r.

${ }^{63}$ RAE, Diccionario de Autoridades...cit., t. I, Madrid, Francisco del Hierro, 1726, p. 523, voz "azul turquí".

64 "Una caxa en mué azul celeste, cuio tocador se compone de treinta y ocho piezas, y amás un cuchillito, unas tixeras y tres auxas, con peso todas las piezas es de quatrocientas sesenta y ocho onzas de plata. Y declaró el dicho Señor Conde y sus familiares que estavan presentes el mismo que se travaxó en Milán. A.H.P.Z., José Domingo Andrés, 1743, ff. 511r-512v

${ }^{65}$ El llamado lienzo varietado o lienzo de Flandes es un género ordinario que se usa para fundas de colchones y para las cortinas de puerta de las dependencias funcionales, cocinas, repostes, bodega o corrales.

${ }^{66}$ Entre 1760 y 1790 se usa el cotón listado en azul y blanco. Hasta 1804 es el tejido más utilizado en cortinas, cenefas textiles y asientos, seguido de lejos por el cotón de nubes. En la última década del siglo hay menciones a cotón listado en verde y blanco.

${ }^{67}$ Un caso reseñable es la casa del coronel de infantería Dionisio Soler. Salvo varias mesas y estantes de color caoba, los espacios de recepción tienen mobiliario y molduras en azul con dorado de basto, tanto la sillería como las numerosas rinconeras. A.H.P.Z., Manuel Gil y Burillo, 1798, ff. 87r.-89r. En verde se pinta solo la madera del catre. 
${ }^{68} \mathrm{El}$ interior que inaugura esta tendencia unificadora es la pieza del quarto nuevo de las casas del impresor don Luis de Cueto, con todos los muebles, cenefas y molduras en azul y oro a juego con cortinas y tapizados de damasco celeste. A.H.P.Z., José Antonio Ramírez y Lope, 1760, ff. 181v.-193r.

${ }^{69}$ Con el porcelana de la sillería en las casad de la viuda doña María García. Vid. nota 21.

${ }^{70}$ El "quarto nuevo" del impresor don Luis de Cueto serviría para ilustrar la combinación de mobiliario azul con tejidos rojos mientras que el cuarto principal de doña Manuela Boyra presenta mobiliario y cenefas de charol guinda con cubiertas de cotón azul y otros complementos en damasco carmesí. A.H.P.Z., José Antonio Ramírez y Lope, 1760, ff. 181v.-193r. y A.H.P., Pascual de Almerge, 1788, ff. 77r.-86v, respectivamente.

${ }^{71}$ Muerto en 1654, el catedrático de la Universidad Sertoriana de Huesca, Martín Funes y Lafiguera, llegó a ser confesor de Felipe IV. La universidad oscense encargó su retrato a Luis Muñoz Lafuente en 1791. Hoy se conserva en el Museo de Huesca.

${ }^{72}$ Curiosamente, los cobertores de felpa negra pertenecieron a dos presbíteros, Mossen Joseph Hernández y Mossen Joseph Caseda, A.H.P.Z., José Domingo Andrés, 1747, f.257r.-260r y A.H.P.Z, 1748, José Cristóbal Villarreal, ff. 256v.- 257v. Un "doselico de phelpa negra con un Santo Cristo de pie" se hallaba en el quarto del infanzón y maestro tafetanero Ypolito Juan Pomes.

${ }^{73}$ CREIXELL, Rosa María, Cases Grans..., cit., p. 355.

${ }^{74}$ Ibídem.

${ }^{75}$ El primer ejemplar perfectamente descrito aparece en las casad de doña Josepha Moneba, A.H.P.Z., Juan Antonio Loarre, 1713, ff. 473r.-476v.

76 "Covarrubias siente es voz Flamenca o Alemana, que sale del verbo Griffen, que significa llorar", RAE, Diccionario de Autoridades...cit., t. III, 1732, p. 81.

${ }^{77}$ Por ejemplo, "Un cobertor de cama de Indiana guarnecido de su cenefa color ceniza", Inventario del mercader Manuel Torres y Costa, A.H.P.Z., Joaquín Marín y Luna, 1804, ff. 85r.-89v.

${ }^{78}$ Entre los géneros del corredor Mariano Fornés y Árboles, A.H.P.Z., Manuel Borau de Latras, 1796, ff. 101r.$113 \mathrm{v}$.

79 "Esta capa es de un color gris ceniciento semejante al del ratón, en la que los cabos y extremos son comunmente negros ó bastante oscuros". EN VILLA Y MARTÍN, Santiago de la, Exterior de los principales animales domésticos..., cit. p. 401.

Fecha de recepción: 13 de octubre de 2015

Fecha de revisión: 29 de octubre de 2015

Fecha de aceptación: 11 de noviembre de 2015 